\title{
The More the Merrier? The Reaction of Euro Area Stock Markets to New Members
}

\begin{abstract}
The adoption of the euro is a crucial turning point for the economy of any EU member and the culmination of a long process of exchange rate management and macroeconomic convergence. But how does the prospect of euro area enlargement play out in the countries that have already adopted the euro? Are new members seen as a way to expand the club of like-minded countries, or are they perceived as a threat to stability, either because there exists a moral hazard risk from the side of old members to adopt riskier behavior on behalf of new members or vice versa? This paper looks at the effects of the news of the euro's adoption event in new members on the stock returns of nineteen euro area countries, employing both an event study methodology and APARCH modeling to capture and test the form of responses of European financial market volatility. Our results show that markets were indeed pleased when new members joined the euro area, with negative responses due solely to local conditions rather than euro area-wide travails. In our most interesting finding, the expansion of the euro actually helped to dampen local market volatility in the post-crisis period in the founding member states, while euro adoption quelled volatility both pre- and post-crisis for non-founding members.
\end{abstract}

Keywords: euro, currency union, asymmetric effects, event study, APARCH, volatility

JEL Codes: G15, F36, F33 


\section{Introduction}

The introduction of the euro is the biggest step that a European Union Member State can take towards economic integration with its fellow members. The benefits of euro accession and why a country would wish to accede have been well-explored in the literature, including the lowering of transaction costs due to a common currency (Hurník, et al., 2010), a reality which should improve overall firm performance (especially for exporters). Involvement in the single currency should also help to increase competitiveness through price transparency (Ottaviano, et al., 2009), while the euro's presence should help to drive macroeconomic convergence and reduce the "volatility of macroeconomic fundamentals of the historically unstable European economies" (Morana \& Beltratti, 2002, p. 2048). Additionally, other authors have conjectured that the euro would improve allocative efficiency and provide more space for risk-sharing (Sørensen \& Yosha, 1998). Finally, as stock returns in a currency union should be dependent on expectations regarding future returns, interest rates, and risk premiums (Bekaert, et al., 2013), euro adoption should also presumably feed into lower stock volatility (Kim, et al., 2015).

These positive effects have been mooted almost solely for the country that is acceding to the euro area (EA), however, leaving little evidence on how existing members would view the expansion of the single currency zone. This is an important point, as the incentives of existing euro area members are to jealously guard the macroeconomic stability of the union and not allow new members who may upset that balance. Put another way, with monetary policy being outsourced and if the benefits of the euro include lowered transaction costs and dampened volatility, there is a massive incentive to only admit members who will continue these conditions.

Unfortunately, as the events in Greece from 2009 onward have shown, there is a measure of asymmetric information regarding those joining the euro area, as it is not always easy to distinguish which countries will help maintain stability and who can potentially be problematic for the conduct of monetary policy. In such a situation, European capital markets, and especially those in existing euro area states, have a role to play in transmitting information on the desirability of the next addition to the currency area (as suggested in Bhanot, et al. [2014] and Avalos [2016]).

The valuable nature of this informational effect can be attributed to the fact that the actual introduction of the euro is the last step in a long journey of legislative and economic alignment with existing euro members, a journey beginning with behind-the-scenes negotiations and continuing through a public announcement of a country's planned accession and internal political debates approving the move (Pechova, 2012). As this process continues, markets may express their 
judgments via volatility effects and negative returns surrounding both the announcement of a new member and the actual accession of that country to the currency union (Bartram \& Karolyi, 2006). Moreover, these judgments may not be static but rather conditional on the timing of the introduction of the currency (Bris, et al., 2008). In particular, prevailing economic conditions in EA countries could have a sizeable impact on EA stock markets, with favorable economic conditions likely to induce markets to see additional euro area countries more positively and poor conditions (i.e. a financial crisis) creating much more uncertainty.

Despite this firm theoretical grounding, there is a noticeable gap regarding the effects of the introduction of the euro in the extant literature on the aggregate response of financial markets of existing Member States. Indeed, the focus of the existing research on the euro's introduction is mainly concerned with financial convergence and linkages after the euro has been adopted (Bartram \& Karolyi, 2006; Bartram, et al., 2007; Alexandrou, et al., 2011) or the how cross-country differences in industry composition affected the response of particular European economies (Bekaert, et al., 2007; Eiling, et al., 2012). The omission of the aggregate level effects is puzzling, as the macroeconomic "news effect" on stock returns and volatility at the market level has been extensively explored; indeed, this prior research provides a solid foundation for theorizing on the possible effects of an entire country's market reactions to the expansion of the euro area.

The purpose of this paper is to take up the challenge of Green \& Bai (2008, p. 445) for "more detailed research on capital market impacts of the new currency" and fill the euro area-sized hole in the literature regarding the effects of euro adoption on financial markets. In particular, we are the first to our knowledge who examine if the adoption of the euro in new countries harmed or helped stock markets throughout the EA: we believe that accession to the euro would have been welcomed in the country which was acceding, but the effect on existing euro members would be conditional on the country that was joining. Furthermore, given the centrality of the euro crisis to public opinion on the viability of the common currency, we assert that responses pre-crisis would have been different than post-crisis, also conditioned on the size of the country and the general macroeconomic environment in the euro area.

This research question is explored here using event study methodology (MacKinlay, 1997; Campbell, et al., 1997; Green \& Bai, 2008) and a behavioral arbitrage pricing model (Lemmon \& Portniaguina, 2006; Ho \& Hung, 2009; Chandra \& Thenmozhi, 2017) with asymmetric powerARCH (APARCH) effects (Ding, et al., 1993). Our results show that markets were indeed pleased when new members joined the euro area, with negative responses due solely to local conditions rather than euro area-wide travails. In our most interesting finding, the expansion of the euro actually 
helped to dampen local market volatility in the post-crisis period in the founding member states, while euro adoption quelled volatility both pre- and post-crisis for non-founding members. Despite heterogeneity in responses, this result is robust to several behavioral and macroeconomic controls.

The rest of the paper is organized as follows: Section 2 explicitly formulates our research hypotheses in the context of the extant literature, while Section 3 describes the data and lays out an estimation strategy. Section 4 provides results and a discussion and Section 5 then concludes.

\section{Euro Adoption and Responses to Joining the Club}

As noted, the effects of euro adoption on the aggregate stock markets of both acceding and existing euro area countries have not been explicitly detailed in the literature. Only two notable exceptions stand out, with Green \& Bai (2008) and Morana \& Beltratti (2002) examining respectively the effects of the euro on stock market returns and volatility. Green \& Bai's (2008) work utilized event study methodology to capture the effects of euro adoption at its inception in January 1999 on EA stock markets. Considering the euro adoption as a market reform rather than a completely anticipated event, they report significant cumulative abnormal returns in both euro and non-euro European stock markets after the euro was introduced in all founding Member States. Interestingly, Green \& Bai (2008) do not look at market volatility after the euro was actually adopted, a key theme which was explored instead in Morana \& Beltratti (2002). Exploring the changes in market volatility in France, Germany, Spain, Italy, the UK, and the US following the euro introduction event, Morana and Beltratti found a brief burst of volatility but a longer-term significant reduction in volatility in the Italian and Spanish stock markets.

With these papers the only previous empirical evidence on the effects of euro accession on capital markets, we must look elsewhere in order to tackle the question of how existing euro area markets react to news of new members. Indeed, our approach is to infer these effects from clues spread across three separate research strands in finance and economics: first, news effects and the linkages between capital market movement and macroeconomic news as typified in papers such as Mitchell \& Mulherin (1994) and Hayo \& Kutan (2005); second, spillover effects across capital markets as shown in a European context in recent work from Fedorova \& Saleem (2010) and Caporale, et al. (2016); and finally, asymmetric responses to particular news items, conditioned on the type of news and the source (Veronesi, 1999; Boyd, et al., 2005). Amassing the lessons from this research, we have fashioned three hypotheses regarding how the adoption of the euro would impact both new and existing members after controlling for changes in the euro-area market's returns as a whole. In reality, 
we create an analog of previous firm-level analyses, by treating the corresponding stock market returns of both founding and non-founding EA member states as particular assets that display normal and abnormal behavior; the abnormal behavior of market-wide returns are then be used for the inference of hypotheses.

H1: News of or the actual introduction of the euro has a beneficial effect on the returns and volatility of the stock market in the country which introduces the euro.

Fundamentally, under the assumptions of efficient markets and identically informed investors behaving rationally, stock prices should depend on expected cash flows, the discount rate, and stockor market-specific risk premium. This hypothesis takes this reality into account, theorizing that effects of joining the euro imply a rational response by financial markets to possible changes in the long-term value of the currency, lower inflation volatility (Mongelli \& Wyplosz, 2008), greater earnings potential due to access to larger markets (Badinger \& Breuss, 2009), and lower transaction costs (Hurník, et al., 2010). Moreover, the adoption of the euro may significantly change the business environment of the countries acceding to the common currency, making them more open for foreign investment; for smaller countries especially; acceding to the EA could have major benefits in terms of access to capital and help to dampen financial volatility via financial depth (Agénor, 2003). On the other hand, euro adoption may also increase exposure to other euro area markets, leading to an increase in volatility beyond that generated by domestic events (Billio \& Pelizzon, 2003).

We assume for this paper that the news of euro adoption should be greeted warmly by financial markets within the acceding country, leading to higher returns at both the announcement of the euro's adoption and (lesser) at the actual adoption of the euro. Given the long lead-in process to euro adoption, it is anticipated that markets will price in the benefits of the euro before its introduction, but that the actual step in joining the club will occasion some abnormal returns for a time. In line with Morana \& Beltratti (2002), we also assume that euro adoption will have a longer-term dampening effect on financial markets in the home country, mainly through a lowering of transaction costs (Bartram \& Karolyi, 2006; Hau, 2006) and convergence in financial development (Kim, et al., 2005).

H2: The effect of news or introduction of the euro within a country was a different pre-global financial crisis and post-crisis.

The linkage between extant economic conditions and the stock market has a long pedigree in financial economics, going back to Chen, et al. (1986) and further advanced by Cutler, et al. (1989) and McQueen \& Roley (1993). McQueen and Roley's insights are the asymmetry of market responses to different types of news and how these responses are dependent upon the overall 
economic environment. In particular, the authors concluded that good news related to real economic activity is generally damaging the stock market returns if overall economic conditions are already good. To put it another way, unanticipated hikes in economic activity in a weak economy may raise expectations about future economic activity and cash flows, but the same information in a strong economy does not necessarily lead to higher expected cash flows.

Veronesi (1999) formalized this response in a model, which explicitly allowed variation in investor responses to dividend news in different states of the economy. If the tone of the macroeconomic news goes against current market directions, it generates a high level of investor uncertainty about the state of the market and its future direction, leading investors to discount the new information at a higher rate. However, this model also assumes a measure of asymmetry, as investors overreact to bad news in good times and underreact to good news in bad times. In good times, bad news produces high stock price volatility and higher uncertainty about a firm's fundamentals, causing stock prices to fall further than the reduction in expected future returns that news may bring (overreaction). Whilst good news in bad times also produces a higher level of investor uncertainty on future cash flows (reflected in increased volatility of stock prices), dampening any upward adjustment in stock price and keeping such adjustments lower than the increase in expected cash flows (underreaction). This model is in line with psychological assessments of how people filter good and bad news differently (Baumeister, et al., 2001).

Veronesi's (1999) model has stood up well to empirical tests, with confirmation of his thesis to be found in the work of Flannery \& Protopapadakis (2002), Adams, et al. (2004), and Boyd, et al. (2005), concerning the news on unemployment. Minor exceptions to this consensus exist: Docking \& Koch (2005), in their investigation on the sensitivity of US investors' reactions to dividend announcements under different market conditions, found that the congruence of recent market direction and volatility were statistically and economically significant for bad news in good markets, but not for good news (i.e. there was no evidence of underreaction, only overreaction). Similarly, Andersen, et al. (2007) explore asset price responses to the fundamental economic news in the U.S., German and British stock, bond and foreign exchange markets, finding symmetrical responses to bad news during expansions and good news in recessions. Brenner, et al. (2009) also find that positive surprises have a stronger impact on stock returns than negative surprises in the US market. However, despite these findings, more recent work by Knif, et al. (2008) concerning inflationary news, Birz \& Lott (2011) on both GDP and unemployment news, and Garcia (2013) on all types of financial news during a recession have also confirmed the underlying precepts of the Veronesi (1999) model. 
[Figure 1 here]

In the euro area, it is anticipated that market reactions to new euro entrants followed a similar pattern as Veronesi's model, with the breakpoint being the global financial crisis. A look at the data from the comparative experiences of Slovenia and Lithuania could help to illustrate these effects. Slovenia adopted the euro in 2007 (pre-crisis) to broad popular support within the country, with more than a third of Slovenian businesses expecting positive results (Eurobarometer, 2007). The Slovenian stock market was also welcoming, with low levels of volatility throughout 2006 in tandem with generally placid EA stock markets (Figure 1). Removing a spike in volatility six months after the adoption of the euro due to the country's presidential elections, the remaining movement in the volatility of Slovenian log stock market returns closely follows movements in their new EA counterparts.

\section{[Figure 2 here]}

On the other hand, Lithuania joined the EA in 2015, immediately following a period of incredible turmoil surrounding Greece and its possible exit from the EA (turmoil that Lithuania seemed strangely impervious to, see Alexakis, et al. 2016). Moreover, during the run-up to the introduction of the euro, the Lithuanian public was considerably wary of the changeover, with only $44 \%$ of respondents in a poll believing that the Euro would have positive consequences for the country (Eurobarometer, 2014; Eurobarometer, 2015). However, while the Lithuanian stock market was incredibly calm when the euro was actually introduced (Figure 2), the euro area exhibited high spikes in volatility around this event (with the largest jump in over a year seen immediately following the euro's adoption). While other major macroeconomic news was occurring around the same time (in particular the Greek elections on January 25 and the initiation of the ECB's version of quantitative easing), they were also related directly to the expansion of the euro area; such increased volatility was thus perhaps signaling that markets were not so sanguine about adding another, poorer country to the mix at a time of already-heightened uncertainty. ${ }^{1}$ Additionally, the time to joining the euro from the announcement of joining in Lithuania's case was one of the shortest on record (July 23, 2014, to January 1, 2015) - perhaps a consequence of the earlier failed attempt to join the euro in 2007 (Markevičiūtė \& Kuokštis, 2016) - meaning that euro area markets may not have had time to process the information (Eurobarometer, 2015). Given Lithuania's long history of

\footnotetext{
${ }^{1}$ Indeed, the Greek election campaign was fought entirely on the question of a bailout from the EU and resulted in a victory for the anti-bailout forces. See Koliastasis (2015) for further details.
} 
attempting to joining the euro-area and failing, it is likely that Lithuania finally fulfilling its accession criteria also may have been somewhat of a surprise (Backé \& Dvorsky, 2018).

Beyond this eyeballing of the data regarding two separate euro accession countries, there is also some econometric evidence to show state-dependence in how news is absorbed in the euro area. For example, Fernández-Rodríguez, et al. (2015), looking at transmission of volatility through the sovereign bond market of EA states, found that the peripheral EA countries (Italy, Spain, Portugal, and Ireland) triggered volatility spillovers throughout the EA but only after the global financial crisis ("core" EA countries were the source of spillovers before the crisis). Similarly, Koulakiotis, et al. (2016) also find strong volatility and error spillovers amongst the banking sectors in Germany, Greece, Ireland, Italy, and Spain concerning bad news emanating from Greece; more importantly, their findings were also contingent on the state of the economy, with volatility remaining more persistent and widespread after the Greek crisis than before. Given these results, we believe that the market response to euro adoption across the EA will be conditional not only on the country entering but on when a country enters as well.

H3: Adoption of the euro by another country will have an asymmetric impact on the local stock market of existing euro members, dependent on which country is joining.

Finally, Hypotheses 1 and 2 should be uncontroversial, given the large body of literature surrounding currency unions and positive macroeconomic news. However, in tandem with the domestic effect of euro introduction, as we noted above, there also should be effects occurring in the capital markets of countries that are integrated economically and financially with the country introducing the euro. Such effects have been explored in a sizeable and varied literature on the volatility spillover effects of macroeconomic news across large and integrated markets. Engle, et al. (1990) note that spillovers can be thought of as "heat waves" or "meteor showers:" under the "heat wave" hypothesis, higher volatility is seen as a local phenomenon, which does not spread from market to market in any sequential fashion, but a "meteor shower" would see higher volatility spills from one market to the next over the course of the global trading day. The evidence presented by Engle, et al. (1990) is that volatility spillovers tend to follow the "meteor shower" path, a result which has been replicated several times: for example, Connolly \& Wang (1998) argue that macroeconomic news has little return spillover effect across the US, the UK, and Japan, but does have a significant effect on volatility spillovers across the three countries. In particular, they find that foreign news has a stronger impact on the volatility of the local market than local news. Nikkinen \& Sahlström (2004) also find that US domestic announcements (employment reports) have a larger effect on European markets than in the US. More recently, Jiang, et al. (2012), considering the effects of European news on US 
stock markets and vice versa, find comparable results, although they make a distinction regarding the volatility engendered by unscheduled announcements, which tends to be much higher than volatility accompanying scheduled announcements. ${ }^{2}$ Similarly, Kim, et al. (2015) discovered that bad news in the euro area increases volatility in the US and China, while bad news from the US had a paradoxically calming effect on euro area stock markets after the global financial crisis.

Similar to the voluminous literature on spillover effects, there is a well-developed literature on asymmetric effects of news, with bad news assumed to have a much stronger effect on stock market returns and volatility than good news. There has been a veritable torrent of work confirming the volatility-creating effects of macroeconomic news in the past decade, with papers such as Nikkinen, et al. (2006), Brenner, et al. (2009), and Rangel (2011) showing how bad news tends to generate more volatility (in addition to poor returns) than good news, dependent upon country-specific traits. Moreover, the content of the news also has its own magnifying effect on responses: for example, Bomfim (2003) shows that if an announcement contains new information previously not incorporated in stock prices, the volatility of stock markets tends to increase in the short-run.

In each of these cases, however, the volatility transmission of news occurred either within or across countries that had independent monetary policies, currencies, and financial markets. What of the case where monetary policies are integrated into a common currency, even though financial markets remain independent, as in the euro area? Kohonen (2013), echoing Connolly \& Wang (1998), found that local macroeconomic news may be digested more accurately by local investors, but overlapping stock markets such as in the EA can help to increase the number of uninformed investors, thus exacerbating volatility and spillover in a crisis. Bhanot, et al. (2014) provide further empirical evidence, finding that negative news announcements regarding the Greek crisis have had significant spillover effects in other EA countries, with the Netherlands, Spain, and Portugal seeing substantial increases in financial volatility.

This wealth of research begs the question, however, is either the introduction of the euro or its expansion good news or bad news? Our conjectured answer to this question is it depends, mainly on which country is joining. Our hypothesis here asserts that spillover effects, coinciding with news events, should be highly country-dependent (and thus asymmetric), as a country with perceived excellent macroeconomic fundamentals and stability is likely to be welcomed by financial markets of existing euro Member States, while unstable or "bad" candidates could generate higher levels of financial volatility. Markets already do a good job of differentiating amongst the EA Member States

\footnotetext{
${ }^{2}$ Their results are in line with an ex-ante updating of expectations by market participants as the reaction to the anticipated shocks, while unanticipated news implies overreactions reflected in volatility hikes.
} 
concerning their relative risk (Ribeiro, et al., 2017), so it is plausible to assume that acceding EA members would also be under the same scrutiny by stock markets. We thus anticipate that a host of country characteristics (detailed below) would help markets to make such a judgment.

While our paper would be the first to explicitly model this relationship in the euro area, some studies appear to offer additional empirical hints of the existence of this relationship already. Fratzscher (2002) noted that financial convergence (measured by volatility of exchange rates) in the euro area was driven by the removal of uncertainty regarding monetary unification; if this is the case, the converse is likely to be true, i.e. that increased uncertainty regarding the next steps in the monetary union would lead to higher volatility. More recent work from Caporale, et al. (2016) also confirms asymmetrical responses to bad news during the euro area crisis, but also note that the responses were stronger in the PIIGS countries (Portugal, Ireland, Iceland, Greece, and Spain) both during and after the global financial crisis. The authors noted that already at the lower end of the euro area in terms of GDP and financial stability, the introduction of even-poorer countries to the EA after the crisis may have colored the perceptions of these markets unfavorably.

\section{Methodology and Data}

\section{Hypothesis H1}

The hypotheses noted above require different approaches in order to explore the effects of euro introduction on stock markets in Europe. For Hypothesis H1, relating the introduction of the euro to changes in returns in the domestic aggregate stock market, we use an event study approach in the vein of Green \& Bai (2008). The use of event studies is common in the finance literature to assess the impact of particular pieces of news on financial markets (Campbell, et al., 1997), and the adoption of the euro can be considered as a highly significant and only partially-anticipated news event (as noted in the introduction); indeed, euro introduction has the potential to lead to significant changes in the business and economic environment of the introducing country and can alter capital markets, firm strategies, and firm valuation in a manner which is unforeseeable in the medium-term.

However, a possible criticism of this approach is that the euro was widely anticipated, and thus any effects its introduction may have had would already be priced into equity markets well before the date of introduction. Nevertheless, a key point to note, following Green \& Bai (2008), in this paper we distinguish between what actually was anticipated (e.g. the timing of the euro's introduction, "convergence criteria" tests, and conversion rates) and what could not be anticipated, in particular the exact macroeconomic and microeconomic situation of each country at the moment 
of accession. Moreover, the cascading impact of the euro on very different countries being joined together under a single currency also is an effect that could not be anticipated but which financial markets would have had to adapt to across industries and at the country level (hence our emphasis on the aggregated response). Dissimilar fiscal and financial systems in the original Member States and, later, in the accession countries would have required the European Central Bank to alter its monetary policy for the euro, creating unanticipated consequences for markets. Additionally, at the microeconomic level, the euro introduction and/or its adoption was equivalent to structural financial reform, implying that firm-level information was not fully reflected in market variables until the structural shift itself was realized (Green \& Bai, 2008; Eiling, et al., 2012). These arguments suggest that investors still had to deal with uncertainty in addition to the anticipated information available regarding the euro. This reality means that the reaction of market participants to euro introduction/adoption events still contains important nuggets of information that have not yet been mined but which can be visible in the aggregate abnormal responses of European markets.

The event study utilized in this paper follows the conventional market model formulation (MacKinlay, 1997; Green \& Bai, 2008), while the significance of abnormal returns is inferred through the use of event dummies, pioneered by Karafiath (1988):

$$
R_{k, t}^{\prime}=\alpha_{k}+\beta_{k} \cdot M_{t}^{\prime}+\sum_{h=T-u}^{T+v} \gamma_{k, h} \cdot D_{h, t}+\varepsilon_{k, t}
$$

Raw data on daily stock indices $\left(P_{k, t}\right.$ in the country $k$ on trading day $\left.t\right)$ in 19 -euro area countries is sourced from the Bloomberg database over the period January 1, 1996, to May 18, 2015, and transformed into logarithmic returns by: $R_{k, t}=\ln P_{k, t}-\ln P_{k, t-1}$.

To proxy for "normal" euro area market returns, we utilize market returns captured by log returns $M_{t}^{\prime}$ from the Eurostoxx 50 index, the leading blue-chip index for euro area exchanges, also sourced from Bloomberg. The inclusion of the Eurostoxx 50 index is taken to represent the euro-area "market," a connected but supra-national exchange and an effective proxy for normal returns across the whole euro-area; the individual country markets are then compared against this total euro-area market to understand "abnormal" returns. This is a key difference from firm-level applications of the event study (MacKinlay, 1997) yet is fairly similar, as firm-level event studies utilize one firm against a total market, while in this example, we use one country level market against a total euro-area market. The statistical formulation of the problem remains the same as in the standard application of event studies (Campbell, et al., 1997). ${ }^{3}$

\footnotetext{
${ }^{3}$ Both a participant at one of the conferences this paper was presented at and an anonymous reviewer noted that country betas might have shifted over this period. However, the use of CAPM models in event studies such as this are exceedingly
} 
Following Green \& Bai (2008), we account for the differences between calendar time models, where returns are generated continuously, and trading time models, where returns are different after weekends and holidays (a crucial point, given that our research question is explicitly on returns surrounding a specific date - thus, we need to filter out any other effects which may have come because of that date). The daily data on returns are adjusted using the geometric mean of returns on Mondays and after holidays: $R_{k, t}^{\prime}=R_{k, t} / n_{t}$ and $M_{t}^{\prime}=M_{t} / n_{t}$, where $n_{t}$ is the difference in calendar days between two observed trading days. More importantly for our purposes, the presence of abnormal returns after the event is captured utilizing $u+v+1$ daily dummies $D_{h, t}$, equal to 1 when $h=t$ and zero otherwise, where $u$ and $v$ are the corresponding numbers of days before and after the official event date $T$ and $h$ is a corresponding date within the event window. ${ }^{4}$ The estimation sample consists of one trading year estimation period and an event window $(T-u, \ldots, T, \ldots, T+v)$, where $T$ is the official event date, either the day of the news announcing the euro's introduction/adoption or the actual introduction/adoption itself. Data on the official government announcement of the introduction of the euro is collected from the official EU website http://europa.eu/. Similarly, the news dates on the intended euro introduction in the nineteen current euro area countries (11 founding and 8 non-founding members, see Appendix 1) also comes from EU sources. Descriptive statistics for daily and monthly logarithmic returns and squares of monthly zero-mean logarithmic returns, i.e. stock market volatility, are provided in Appendices 2-4.

The dummy variable approach, being equivalent to the standard formulation of abnormal returns, allows us to test for the length of the abnormal responses applying an $F$-test on the joint significance of the parameters $\gamma_{k, h}, h=T-u, \ldots, T+v$. To be consistent with our monthly data analysis, the rationale for which is described below, we set $u=0$ and examine delayed responses up to $v=20$ and 40 trading days ahead, i.e. approximately one and two trading months correspondingly. While admittedly an arbitrary cut-off, we set the post-event period at two trading months as we believe it is enough for the corresponding cumulative abnormal returns to return to normal; moreover, the

\footnotetext{
rare - in a meta-analysis, Holler (2012) notes that $79.1 \%$ of studies use market models, while only $0.7 \%$ of papers surveyed use CAPM. Given the aggregated level of our analysis, and our believe that sector-specific beta trends would be washed out in the aggregate market trend, we follow the overwhelming majority of the literature in not using an explicit CAPM model.

${ }^{4}$ An anonymous reviewer noted that industry composition across European countries is not uniform, and that industry factors may have large returns on specific event dates (a point made by Eiling, et al., 2012). However, this point is immaterial, as even industry-driven responses to euro introduction - especially if that industry dominates a particular country's economy - only validates our hypothesis that the euro introduction would have an impact on a country at the aggregate level. We are not explicitly testing whether or not the transmission channel is industry or country-level, but rather what the response was based on the attributes of the joining country (and not the existing country). Moreover, Eiling, et al. (2012) also do not have any financial crisis data, meaning that the transmission channel may have flipped back to country-level attributes; we make no claim that it has, as it too is still immaterial to our research question.
} 
probability of other, subsequent events not related to euro accession, is relatively low, meaning we can be fairly confident that we are capturing reactions specifically to the announcement or introduction of the currency. ${ }^{5}$

Finally, as is standard in the event study literature, $\varepsilon_{k, t}$ is a zero mean, yet potentially conditionally heteroscedastic error term. Equation 1 is estimated using ordinary least squares (OLS) without robust heteroscedasticity and autocorrelation consistent (HAC) corrections. As noted in Fomby \& Murfin (2005), the application of HAC corrections in the event dummy case might result in misleading inference due to inconsistent estimates of dummy variable parameters $\gamma_{k, h}$.

\section{Hypotheses $\mathrm{H} 2$ and $\mathrm{H} 3$}

While an event study may capture abnormal returns within one country, we are also interested in the linkages between returns, volatility, and macroeconomic shocks (surprises) across countries, as shown in our Hypotheses $\mathrm{H} 2$ and H3. Moreover, there may be bias in the estimated parameters for dummy variables $\gamma_{k, h}$ in the event study methodology Equation (1) if important conditioning variables such as investor sentiment or monetary and macroeconomic explanatory variables (controls) are omitted. Event studies, while being a useful tool, also suffer over longer timeframes as confounding effects or even overlapping events may vitiate the power of the study to pinpoint the exact effect of a particular event. While the event study approach shown above attempts to minimize these issues, as a further check to mitigate omitted variable and confounding problems, we turn to a univariate conditional heteroscedasticity model. The conditional mean of the model is formulated in the spirit of the behavioral arbitrage pricing theory (Lemmon \& Portniaguina, 2006; Ho \& Hung, 2009; Chandra \& Thenmozhi, 2017), which asserts that behavioral factors also play a role in setting asset prices; as a volatility model, it also contains conditional volatility dependence (3) and (4) encapsulated in an error term $\varepsilon_{k, m}$ :

$$
\begin{aligned}
& R_{k, m}=\alpha_{k}+\beta_{k} \cdot M_{m}+\sum_{j=1}^{K} \gamma_{k, j} \cdot D_{j, m}+\pi_{k}^{\prime} \cdot x_{k, m}+\varepsilon_{k, m}, \\
& \varepsilon_{k, m}=\sigma_{k, m} \cdot u_{k, m}, \\
& \sigma_{k, m}=v\left(\varepsilon_{k, m-1}, \varepsilon_{k, m-2}, \ldots, \sigma_{k, m-1}, \sigma_{k, m-2}, \ldots, D_{1, m}, \ldots, D_{K, m}, x_{k, m}\right),
\end{aligned}
$$

\footnotetext{
${ }^{5}$ Finally, this choice mirrors that of Green \& Bai (2008).
} 
where $R_{k, m}$ denotes logarithmic returns in country $k$ in trading month $m$ and $x_{k, m}$ represents a corresponding vector of macroeconomic, institutional, and sentiment controls containing exogenous variables and lags of potentially endogenous variables for the same country $k$.

All macro-economic variables are defined as surprises, meaning the use of corresponding monthly growth rates or first differences for controls with units in percentage points. Unfortunately, as data on macroeconomic variables is, at best, available at a monthly frequency only, to link the different frequencies of the macroeconomic data and stock returns we transform the daily stock data into monthly logarithmic returns taking the difference between the first and the last trading day observations of the trading month and multiplying it by 100 to increase the convergence rate of optimization algorithms. This approach, while sacrificing some information clustered around the actual event and captured in daily data (as is already captured in the event study), allows for a wider range of macroeconomic, behavioral, and inertial controls to be included in Equation 2. ${ }^{6}$ Moreover, given the magnitude of the event, we anticipate that market reactions (and in particular volatility) will last for more than one day, and thus can be captured in a monthly aggregation.

The event dummy variable $D_{j, m}$ in Equation 2 then allows us to estimate the effect of the domestic euro introduction news or events on the local market returns and volatility, set at 1 during the event month and zero otherwise. Innovations $u_{k, m}$ are assumed to be Gaussian, while all asymmetries are defined by the conditional variance function $v($.$) . To estimate Equations (2)-(4),$ we utilize the statistical package gig written by Lucchetti \& Balietti (2011).

The set of controls $x_{k, m}$ includes spillover effects on domestic markets, which are captured by one-month lags of log-returns from the entire euro area $\left(M_{m-1}\right.$, as in Equation (1) and taken as the Eurostoxx 50). This approach, as in Fedorova \& Saleem (2010), allows us to ascertain the impact of the news or events of the introduction of the euro in foreign markets on domestic market returns and volatility. Similarly, we anticipate that a significant result on $M_{m-1}$ also demonstrates an inertial effect present in foreign and domestic stock returns.

Additional behavioral controls are proxied by the inclusion of an economic sentiment indicator (ESI) for either the whole EU (ESI EU), for the euro area (ESI EA), or at the individual country level

\footnotetext{
${ }^{6}$ Given our focus on the information that is encapsulated in the data, we also eschew the use of linear interpolation of monthly macroeconomic aggregates, as this would introduce information which may actually be at odds with the data itself. Indeed, macro news has many attributes which we feel are superior to interpolation, as news is: (1) calendar dependent with substantial publication lags; (2) realization of news is unknown before the announcement; and (3) events themselves are unknown before announcements. Finally, ex-post digestion of macroeconomic news includes the fundamental and non-fundamental factors that drive the stock market returns in the short run, and as such helps us to distill euro introduction effects more precisely.
} 
(ESI), all of which were sourced from Eurostat. Finally, macroeconomic controls include several measures, which can influence firm valuation, including Eurostat and the ECB data on the narrow euro money supply (M1), the US dollar and euro exchange rate, industrial production indices, harmonized consumer price indices-based inflation rates, and unemployment rates. For computational simplicity, we will assume that the conditional volatility equation (4) has no other controls other than the event dummy variables.

To model the conditional volatility, we rely on an asymmetric conditional heteroscedasticity model from the asymmetric power-ARCH (APARCH) family, introduced in Ding, et al. (1993). The conditional variance (4) is specified as:

$$
\sigma_{k, m}^{\delta_{k}}=\omega_{k}^{\prime} x_{k, m}+\sum_{i=1}^{q} \alpha_{k, i}\left(\left|\varepsilon_{k, m-i}\right|-\gamma_{k, i} \varepsilon_{k, m-i}\right)^{\delta_{k}}+\sum_{j=1}^{K} \kappa_{k, j} D_{j, m}+\sum_{l=1}^{p} \beta_{k, l} \sigma_{k, m-l}^{\delta_{k}}
$$

where the power parameter $\delta_{k}$ performs a Box-Cox transformation of the conditional standard deviation and is assumed to be positive (typically ranging between 0 and 2). Closer to zero values of this parameter will indicate a smaller sensitivity to outliers, i.e. bigger news effects. Special values of these parameters give rise to the particular cases, which, hence, could be tested. Seeking a more parsimonious model, the values of $p$ and $q$ are conventionally set to 1 or 2 , although deeper dependences are also possible.

The most widespread conditional volatility model utilized in an examination such as this is a GARCH model, pioneered by Bollerslev (1986), which is a special case of the APARCH model and imposes constraints of $\delta_{k}=2, \gamma_{k, j}=0, j=1, \ldots, q$. However, a key drawback of GARCH is its symmetric response to positive and negative shocks, which may not be the case concerning the introduction of the euro. In particular, asymmetric responses of equity returns to news such as euro introduction are caused by leverage effects, which force debt to equity ratios to rise because of the decline in equity value. This, in turn, affects investors' expectations of future cash flows and their perceptions of risk, as investors are likely to perceive their future cash flows as being riskier. The asymmetry in responses is also explained by the "volatility-feedback" hypothesis, which argues that if expected returns increase with rising stock volatility (likely to happen with the introduction of the euro), then stock prices should fall given the constant dividends. Bearing these arguments in mind, we include parameter $\gamma_{k, j}$ to capture asymmetric effects and we will test if $\gamma_{k, j}$ is significantly different from zero (Bekaert \& $\mathrm{Wu}, 2000)$.

The theoretical attractiveness of the APARCH specification shown in Equation 5 must be weighed against its computational intensity, i.e. solving an asymmetric non-linear problem estimated by maximum likelihood methods and using techniques to approximate the derivatives of the 
likelihood function, an intensive process even when a number of controls is small ${ }^{7}$. To overcome this difficulty, we propose a two-step approach: in the first step, we assess which particular case of the volatility equation is the most probable according to APARCH estimates, using a parsimonious set of controls. For the second step, we re-estimate Equations 2, 3, and 5 as a system but using other streamlined APARCH models, including a conventional symmetric GARCH model, Geweke (1986) and Pantula (1986) asymmetric log-GARCH model (where $\delta_{k} \rightarrow 0$ ), Glosten, et al. (1993) GJR model $\left(\delta_{k}=2\right)$ and Zakoian (1994) TARCH model $\left(\delta_{k}=1\right)$ and TARCH's symmetric counterpart, TS-GARCH model.

\section{Empirical findings}

\subsection{Event study}

\subsubsection{Founding Members}

We begin with the event study methodology of Equation 1 to trace the effects of the euro's introduction on its founding members (Hypothesis 1). One of the immediate distinguishing factors of the founding members from members who were to join later (other than the possible endogeneity in timing the introduction of the euro) was the long run-up to the euro, and the reforms required, resulted in two discrete and separate announcements regarding the euro's introduction before the currency was even actually introduced. The first announcement on the euro's introduction was made simultaneously across the eleven founding members on June 17, 1997, with the adoption of the Stability and Growth Pact on fiscal rectitude within the euro area, while the second announcement, the European Council's decision acknowledging that eleven countries had met the necessary conditions to introduce the single currency on 1 January 1999, occurred also simultaneously across EU states on March 3, 1998.

\section{[Table 1 here]}

Table 1 shows the result of the event study surrounding these two separate announcements, with Panel A examining abnormal returns surrounding the first announcement in 1997 and Panel B the returns associated with the second announcement in 1998 (Panel C shows the results surrounding the

\footnotetext{
${ }^{7}$ The problem becomes computationally more difficult in the presence of controls and dummy variables, when moving to more general omnibus of symmetric and asymmetric family GARCH models (Hentschel, 1995) or fractionally integrated APARCH (Tse, 1998). Moreover, our approach here is meant to capture short-memory processes rather than the long memory persistence embodied in fractional integration, which also argues for using a more "conventional" APARCH estimation strategy.
} 
actual introduction of the currency in 1999). The results indicate that, even after accounting for highly significant and positive market conditions, the average residual daily returns varied from -0.0012 to 0.0014 (any statistically significant deviations from the expected values are conventionally interpreted as abnormal returns or ARs). Despite the simultaneous announcements and introduction of euro events across the founding members, we see heterogeneous responses across Member State stock markets: this can be clearly seen in the reaction to the first announcement event, shown in Panel A, which appears to encompass country-specific attitudes towards the euro (euro enthusiastic or eurosceptic), a trait which can also be observed in the country's cumulative abnormal returns (CARs, shown in Figure 3).

[Figure 3 here]

For example, German and Austrian financial markets, geographically proximate and economically interlinked, appeared to welcome the first announcement event, as did future members of the euro area situated on the periphery of the EU (Portugal, Ireland, and Finland). On the other hand, initial positive (abnormal) responses in Belgium, France, and Spain dissipated within a few trading weeks to a eurosceptic view, while Dutch markets showed little response.

Overall, the analysis of individual abnormal returns and the heat map shown in Figure 4 show that it took about two trading weeks for markets to form a response to the news of the euro's introduction or, alternately, to wait for lingering uncertainty surrounding the announcement to be resolved. After this initial two-week period, the second wave of ARs was observed approximately five trading weeks after the announcement, an effect that actually shaped and strengthened existing behavioral patterns.

[Figure 4 here]

Panel B of Table 1, showing market responses to the second announcement of the euro's introduction, reveals behavioral shifts in several countries. Austria and Finland continue to show positive CARs, but significant negative CARs can be observed in the second trading month for German and Irish markets. Dutch traders again responded neutrally, with slightly negative, but insignificant daily ARs, and on average, delays in responses were higher for the second announcement (except in Ireland). As shown in the heat map, and unsurprisingly, financial markets were also less surprised by the second announcement compared to the first announcement, as the daily ARs were mild or neutral and much more delayed as compared to the first round. 
Finally, Panel $\mathrm{C}$ in Table 1 shows the response of founding member financial markets to the actual introduction of the euro. Immediately, we can see that euro area markets responded much faster, as the first abnormal returns were already detected within the first and second trading weeks. Significant negative cumulative reactions were observed for the small open economies of Belgium and the Netherlands, while Austria, Finland, and Portugal responded positively (but, again, the Austrian market's CARs were found to be statistically significant). According to the heat map in Panel C, the reaction of the largest euro-area economies - Germany, France, and Italy - in this case, was neutral, signifying that information regarding the euro introduction had long been priced-in.

In sum, these findings confirm Green \& Bai's (2008) argument that the introduction of euro was a well-known and anticipated event of the third stage of EMU, as all founding members were required to meet the convergence criteria for monetary and fiscal policy and inflation to be an eligible member for EMU. However, the schedule of the third stage was flexible and could have started between 1996 and 1999, and only the countries meeting the criteria could join the euro area. Therefore, there was some uncertainty about the number of joining countries, the timing, and the conditions to be imposed on the joining countries and the impact of the euro introduction on economies and markets of the joining countries (it is possible that this uncertainty could have been offset with the news of the euro conversion rates fixed in May 1998, announced before the conversion itself). Our results show that there was indeed still some uncertainty, as there was an asymmetry in market responses, dependent on a particular country, resulting in either observed negative or positive CARs after one or two trading months. Unfortunately, Table 1 shows that this effect was mainly statistically insignificant, with significance observed only in a few small and open founding members (Austria on the positive side and the Netherlands and Belgium on the negative side).

Indeed, Austria is the only country where the stock market responded significantly positively in all 3 panels. As it will be shown in section 4.2, the deviation from historically-observed expected returns was mostly led by increases in the domestic economic sentiment index, implying that Austrian traders overreacted to euro events and the nature of the abnormality is a behavioral feature divorced from fundamentals. Such trading behavior appears to have been influenced by the winding path of Austria to the euro (Hochreiter \& Tavlas, 2005); in particular, the idea of euro area accession began fairly early with debates on the Exchange Rate Mechanism (ERM) and confidence that Austria would be able to fulfill interest rate and inflation rate criteria (but some uncertainty regarding the country's fiscal path). However, the collapse of the government in 1995 jeopardized Austria's ability to adopt the euro in the first wave precisely on fiscal grounds, and the successor government had to implement a fiscal consolidation plan to achieve the euro area fiscal criteria by 1997. In this sense, Austrian 
traders appeared to view the overall sound fiscal policy immediately prior to the euro as locked-in, considering the 1992-1995 fiscal deficits as a temporary phenomenon that euro membership would prevent a return to.

Such a response played out almost entirely in reverse in the Low Countries, which did not undergo such a drastic fiscal consolidation prior to the introduction of the euro. As Table 1 showed, there were pronounced negative reactions in the Netherlands and Belgium to euro introduction, responses we attribute to expected higher uncertainty about convergence criteria, credibility, fiscal policy adjustments, and overall market conditions. ${ }^{8}$ On the other hand, the ex-post analysis shows that there were no fundamental reasons for such pessimistic views: when looking at the fiscal experience in both countries ex-post, Fahrolz \& Mohl (2003) found that the Netherlands and Belgium improved their budgetary positions much faster than the rest of the founding members. For example, in Belgium, the general government financial balance moved from a deficit of 2\% of GDP in 1997 to a surplus of $0.4 \%$ in 2001 , while in the Netherlands, the fiscal stance went from a deficit of $1.1 \%$ of GDP in 1997 to a slight $(0.1 \%)$ surplus in 2001. Moreover, the decrease in the debt-to-GDP ratio in 1997-2001 was around 12\% of GDP for Belgium and 17\% of GDP for the Netherlands, while in France, Luxembourg, and Germany improved just by 1-2\% of GDP.

\subsubsection{Non-Founding Members}

The founding members of the euro were more intimately acquainted with and invested in the euro's launch, perhaps muting the effect on returns due to the greater information available in the long run-up. For non-founding members, however, there was less information (only one announcement) and greater informational asymmetry on the possible consequences of the euro's adoption, an asymmetry which may have been contingent on the timing of the introduction of the common currency (Hypothesis 2). We turn to examine the responses of these eight non-founding members of the euro area, the results of which are reported in Table 2 for the euro adoption announcement news (Panel A) and the actual euro adoption event (Panel B). As an interesting experiment, we also consider two cases where the Member States attempted to enter the euro area but failed to comply with the convergence criteria; the reactions in Lithuania and Greece on their failed first attempts are shown in Panel C.

\footnotetext{
${ }^{8}$ These findings are in line with Green and Bai (2008), where significant negative CARs were also detected for Belgium and the Netherlands.
} 


\section{[Table 2 here]}

As can be seen in Table 2, the non-founding countries have very weak links to Eurostoxx variables, reflected in small and often insignificant elasticity parameters for market returns, and average daily returns vary from -0.005 to 0.0021 . Moreover, the adjusted R-squared values are significantly lower than the $0.36-0.87$ range found for the founding member regressions, due mainly to the inclusion of many dummy variables, which have turned out to be insignificant.

[Figure 5 here]

Overall, the pre-crisis period showed the little-to-no response of local markets to the news on the adoption of the euro, as CARs in this period were slightly negative for all countries which adopted the euro pre-crisis (Greece, Slovenia, Cyprus, Malta, and Slovakia) but insignificant (Figure 5). Similarly, the heat maps are shown in Figure 6 also indicate a neutral stance for most acceding markets pre-crisis to the announcement of the euro's introduction. In these cases, it is also probable that markets had priced in the euro's introduction and, occurring in an era of relative calm, (good) news on the euro had little additional information for investors.

However, and in stark contrast, there are highly significant heterogeneous CARs for pre-crisis euro adoption events. As shown in Panel B of Table 2, markets in Cyprus and Malta - both small and very financially open economies, as shown in Appendix 5 - exhibited a significant level of euroskepticism immediately following the euro's introduction, while Slovenian markets were significantly positive in their assessment of the currency. The reason for these results may be traced back to the exigencies of the countries involved. In the first instance, the island countries of Cyprus and Malta share many similarities: Cyprus has experienced substantial macroeconomic and financial imbalances combined with a growing offshore banking sector not in line with the acquis, while Malta has also been plagued with extensive fiscal issues, including an expanding government deficit and a bloated public sector (Van Eden, et al., 2000). ${ }^{9}$ Second, Malta and Cyprus adopted a similar "big bang" approach in switching over to the euro without a transition period, an abrupt change that created fears in the markets of immediate price increases on the changeover in both countries (Lomas, 2007).

[Figure 6 here]

\footnotetext{
9 However, whereas the Cypriot population mainly welcomed the euro, the Maltese exhibited intense domestic disagreement on even the question of EU membership, and the introduction of the euro also occasioned deep divisions in society.
} 
Contrary to this experience, euro adoption in Slovenia was also highly debated by the public, with opponents and proponents of an early adoption both making their case in the press. While opponents preferred a slow approach with prolonged monetary independence, the views on early adoption dominated and resulted in the government pledging for rapid euro adoption. The ongoing discussions led to presumably higher uncertainty, but, nevertheless, the European Commission (Eurobarometer, 2007) had very positive views on Slovenia' changeover to the euro: one year after the event, $95 \%$ of Slovenians confirmed that the changeover had been smooth and efficient, and $92 \%$ of Slovenians were happy with the level of information they had received from the government. And, although Slovenia also took a "big bang" approach in adopting the euro, it is possible that the optimism surrounding the adoption meant that inflationary fears were subsumed to the perceived benefits that the euro would bring.

A final note about euro adoption pre-crisis concerns Greece, which attempted once before to enter the euro area on its inception but only entered the currency union in 2001. The missed attempt in 1998 as a result of failing to meet convergence criteria, as its inflation rate was $3 \%$ over limit, its interest rates were 11 points above limits, its deficit to GDP ratio was well beyond Maastricht limits, and its debt to GDP ratio was almost double what Maastricht required (Mundell, 1998). By 2001, however, Greece had satisfied the euro area and acceded to the currency amid the post-technology boom slowdown but still a pre-global financial crisis. As Panel C of Table 2 shows, the effect of missing the euro in 1998 was actually greeted by markets as a positive; perhaps in the knowledge that the Greek economy was not yet ready for the loss of monetary policy independence (whether or not it was ready in 2001 is a point to debate elsewhere).

Turning to the post-crisis period, all Baltic countries announced and adopted euro in the postcrisis period with the official euro adoption coming more as a formality rather than an unticipated event; indeed, in addition to the local currency, the Baltics had all become euroized to some extent, with Levasseur (2015) noting that, at the end of 2014, Latvia and Estonia saw approximately $90 \%$ of its banks loans denominated in euros (in Lithuania at the same time, a comparatively smaller $75 \%$ of loans were denominated in euros, along with $25 \%$ of bank deposits). It was perhaps this familiarity with the euro that explains the results in Table 2, namely that the announcement of euro introduction was greeted with little fanfare in Latvia and Estonia, while the introduction of the euro had little effect on CARs in all three of the economies (the heat map in Figure 6 also shows that any reactions to euro news came on the adoption new rather than the actual introduction of the currency).

The only outlier from these patterns is Lithuania. Indeed, Lithuania is a special case similar to Greece, in that it also attempted to enter the euro once previously, in 2006. However, what makes 
Lithuania doubly interesting is that its first attempt came pre-crisis, but its actual accession came post-crisis. As Panel C of Table 2 shows, there was a negative reaction in the markets pre-crisis when Lithuania failed to enter the euro, and the President of Lithuania said in an interview to Euronews.com that this was due to the "unwillingness of the EU to expand the Eurozone." However, the polls at that time showed that approximately one-third of the country was strongly opposed to introducing the Euro, a consistent level of opposition which might explain why the news for Lithuania's actual accession post-crisis also was followed by a significant negative reaction: while 54\% of Lithuanians polled in the Eurobarometer in 2007 (after the first attempt) were still in favor of joining the euro, public polls held before Lithuania's accession revealed that only $44 \%$ of respondents believed in a positive effect of the euro on Lithuania's economy and $48 \%$ of respondents thought it would be negative (Eurobarometer, 2014). This pessimism on the euro almost certainly drove higher levels of uncertainty in Lithuanian financial markets, resulting in negative ARs when the euro introduction was announced. The reality of the euro introduction, however, had little effect, suggesting that the political worries surrounding the euro dissipated when financial markets saw the economic benefits (a finding seemingly confirmed in Alexakis et al. 2016).

\subsection{Univariate conditional heteroscedasticity models}

\subsubsection{Pre-testing of asymmetric effects}

Before directly testing Hypotheses $\mathrm{H} 2$ and $\mathrm{H} 3$, it is important to establish that there is indeed asymmetry in the volatility responses to news of euro introduction, and how this impacts the persistence of volatility and the reaction to outliers. As noted above, we use a two-step process of estimation, first with an unrestricted $\operatorname{APARCH}(1,1)$ model and second with model restrictions for the power $(\delta)$ and asymmetry $(\gamma)$ parameters; to ascertain best fit of the restricted model, we base our choice on minimization of the AIC criterion.

\section{[Table 3 here]}

The results of this pre-specification strategy are shown in Table 3, indicating that asymmetric conditional volatility models are not necessarily appropriate for euro area stock markets. Only five cases out of 18 showed significant asymmetric effects mostly described by TARCH models, with the Austrian stock market best described by a GJR-GARCH approach. The distribution of the significant asymmetric effects was split between founding and non-founding members, with two founding and three non-founding members displaying asymmetric effects to the euro introduction. Concerning 
non-founding members, such effects were found for insular small open economies of Malta and Cyprus, and Greece heavily hit by the global crisis. Somewhat surprisingly, Maltese traders tend to over-react to positive news, while Greece and Cyprus have an asymmetric response that follows more conventional patterns.

Our pre-testing exercise also revealed that more than half of EA stock markets are less sensitive to outliers, since power transformation parameter $\delta_{i}$ is approximately equal to one. At the same time, the persistence of volatility equations is high as the inertia related $\beta$ parameters are relatively higher than $\alpha$. Finally, symmetric GARCH or TS-GARCH models, including three cases for post-crisis entrants (i.e. the Baltic States) are the models of best fit for the rest of the countries under examination.

\subsubsection{Founding Members}

Following Engle, et al. (1990), the next step is to test for the presence of volatility spillover effects conditioned on local and foreign macroeconomic conditions; this first step continues our discussion presented in the event study but includes additional macroeconomic and behavioral controls. As noted above, this new specification includes market spillovers, an economic sentiment index (ESI) for both the EU and the euro area, narrow money (M1), and industrial production, unemployment, and inflation to explain the nature of abnormality observed in daily stock market returns. Using these controls in addition to the euro event dummies (D1news for the first announcement and D2news for the second announcement), we may now proceed to explicitly test Hypotheses $\mathrm{H} 2$ and $\mathrm{H} 3$.

\section{[Table 4 here]}

The results of this expanded model are shown in Tables 4 (the conditional mean) and 5 (conditional volatility) for the founding members of the euro. As can be seen in the respective Panel A of each Table, news regarding the introduction of euro had diverse impacts on the founding members' stock markets, one that appeared not driven by trade linkages (see Appendix 6). The estimates of both conditional mean and variance equations for Germany, France, and Italy (i.e. the drivers of the euro) were unaffected by foreign euro news in both the pre- and post-crisis periods. Indeed, the founding members, in general, saw no significant effects due to foreign euro news in the pre-crisis period, apart from the Portuguese market's enthusiasm for euro adoption in Slovenia. Schukkink \& Niemman (2012) argue that this Portuguese support for enlargement could originate from Portugal's own period 
of accession negotiations, creating a sense of solidarity and identification with the Central and European accession states (indeed, Portuguese preferences for Eastern enlargement were formed already by the late 1980s and have been consistently maintained).

Another interesting case concerns euro adoption in Slovakia, which came in the middle of the global financial crisis and when the ratio between benefits and costs of membership in the EMU were undergoing a significant shift. Given rising uncertainty and financial shocks emanating from the United States, the attractiveness of the participation in the euro area increased for the potential members including Slovakia but also could have reduced the attractiveness of new members to already-existing euro adopters. In line with this conjecture, and as shown in Table 4, the founding members reacted strongly negatively to the euro introduction announcement in Slovakia in July 2008. However, just six months later, when the global financial crisis was well underway, markets reversed themselves and welcomed Slovakia's accession, a consequence of Slovakia's relatively resilient economy (and especially its financial sector). In other words, Slovakia was tested immediately and found to be a worthy addition to the common currency, a fact borne out by the reality that Slovakia was not highly exposed to the subsequent sovereign debt crisis (Kliber \& Płuciennik, 2017). ${ }^{10}$

Moreover, our estimates show that Belgium, Ireland, Luxembourg, and the Netherlands welcomed foreign euro news and exhibited significantly decreased volatility in the pre-crisis period, with Spanish markets, in particular, have higher expected returns and less volatility due to Latvia's announced embrace of the euro. Foreign euro news also appeared to bring lower volatility to Belgian and Dutch markets both in pre- and post-crisis periods. Perhaps not coincidentally, these countries also had the largest financial openness and financial linkages within the EA (as detailed in Appendix 5), meaning that the benefits of expanding the euro (in terms of financial depth and lowered transaction costs) would intuitively be welcomed.

\section{[Table 5 here]}

In contrast to the announcements of the euro's introduction, the actual introduction of the common currency had strong effects in Belgium, France, and the Netherlands (see Table 4, Panel B). Even after controlling for additional factors, the negative results for Belgium and the Netherlands are in line with our previous event study findings, while French markets appeared to be enthusiastic about the euro introduction event. The enlargement of the euro area, on the other hand, created little volatility (Table 5, Panel B), as Austria, Belgium, and the Netherlands had insignificant responses to

\footnotetext{
${ }^{10}$ Of course, there is a measure of endogeneity in this, as Kiohos \& Stoupos (2018, p. 181) argue that "the euro behaved as a shield against the global financial shock for Slovakia."
} 
euro introduction in the pre-crisis period while Germany, France, Italy, Luxembourg, and Portugal saw a significant diminishing of volatility accompanying Slovenia's entry. Indeed, this result is doubly interesting given what we know ex-post, as Slovenia appeared to be a strong candidate for early accession to the euro area ex-ante (Kozamernik, 2004); however, after accession, it saw a rapid deterioration of its fundamentals, mainly due to the global financial crisis but also due to poor policies (in particular delayed pension and labor reforms), and, in some eyes, euro accession itself, which triggered an unsustainable boom in lending (Connolly \& Hartwell, 2014; Guardiancich, 2016). Finally, only Finnish markets seemed skeptical of the euro's introduction in Greece in the pre-crisis period, but a volatility spillover effect was not observed in this market (Table 5).

Our results change noticeably in the post-crisis period, as anticipated in Hypothesis H2. Indeed, euro introduction events in Estonia depressed market returns in Germany, Spain, Luxembourg, and the Netherlands. However, except for France and Estonia, the spread of the euro implied decreases in volatility in most countries; this partially confirms the "heat wave" hypothesis, which argues that market volatility is a local phenomenon and does not spread with the euro adoption event in the other market. However, the "meteor shower" in the case of the euro's spread may have an unanticipated effect, in that the shower is cooling (in terms of volatility) rather than adding heat. Indeed, this result, of asymmetric volatility spillover effects in tandem with foreign euro adoption news, confirms Hypothesis H3.

Finally, the results presented in Panel C of Table 4 suggest that the addition of these controls can help to explain some of the movement in stock markets in the euro area. In particular, common market spillover effects, defined by the lagged value of the Eurostoxx index, are very strong in all founding members with a significant impact on the conditional mean in all countries (varying from 0.68 to 1.07). On the other hand, monthly changes in narrow money were significant in only Italian and Belgian stock markets; similarly, country-level developments in domestic labor markets and rising inflation were limited in significance to Portugal, the Netherlands, Italy, and Germany. In terms of a behavioral effect, Luxembourgish, Finish, and Irish traders have the least correlation with the ESI variables, while southern countries (Spain, France, Italy, and Portugal) are more responsive to ESI in the euro area. This is in line with strong sentiment effects found in Spanish and French stock markets by Corredor, et al. (2013). The results in Panel C also suggest that mostly autoregressive (inertial) or GARCH effects are dominant in the models for founding members, while ARCH effects are relatively small and often insignificant. 


\subsubsection{Non-Founding Members}

Having a long history of euro area membership, we anticipated that the founding members were expected to respond more to the enlargement of the euro area with asymmetric impacts on their stock markets (Hypothesis H3). It is not as evident that the eight non-founding euro area members, having a much shorter span of membership, would also have such effects, but testing this proposition is the purpose of this section (results summarized in Tables 6 and 7).

[Tables 6 and 7 here]

The results reported in Table 6 (Panel A) show no return mean dependence on euro adoption news in non-founding members, which could be explained by the low interdependence of these markets with each other. The insignificant reactions of non-founding members to local euro adoption news both in pre-crisis and post-crisis periods are consistent with the event study results (Table 2) in most of our cases, except for Greece. In fact, Greek traders have a strongly negative response to additional euro members, especially Lithuania, even after controlling for behavioral effects. Such a response was natural given the timing of Lithuania's accession in 2015, which occurred during the "Grexit discussion" and the real worry that Greece could be leaving the euro area (Hodson, 2015). Volatility spillover effects are not observed in Greece and Cyprus concerning euro adoption news, but a decrease of volatility can be seen in foreign euro introduction news for non-founding members similar to founding members, both in the pre-crisis and post-crisis periods. The calming "meteor shower" behavior is observed locally for the tightly interrelated stock markets of the Baltic States, especially in the response to Lithuania as the last of the three countries to join the euro area, while the rest of the cases explored here seem to have responses driven by local (country-level) effects rather than euro accession per se.

The results reported in Panel B of Tables 6 and 7 show no return mean dependence of financial markets of non-founding members on the actual euro adoption event in non-founding members. Only Slovenia exhibits an economically significant reaction to the local euro adoption event, which comports with the results discussed in the event study (see in Table 2). Greek markets appear to demonstrate a eurosceptic response to euro adoption in Lithuania, reflecting prolonged economic difficulties and the risks associated with a possible Greek exit from the euro both before and during the Lithuanian adoption of the common currency. At the same time, Greek traders appeared to care less about the risks of other new entrants of the euro area, as volatility remained unresponsive to the events in both the pre-crisis and post-crisis period (in line with the "heat wave" hypothesis). The volatility model also fails to capture significant responses in Malta and Cyprus, a divergence from 
the event study approach. In fact, the findings indicate the sensitivity of results in some markets to the inclusion of additional controls: strong spillover effects are observed for all non-founding members except Slovenia, while later entrants of the euro area are more responsive to EU economic sentiment index and half of them are positively related to local sentiments. This fact which actually helps us to explain the abnormal effects detected in the event study while illustrating that other factors than the euro are at play. Finally, the local calming spillover effects as the result of euro adoption in Lithuania are again observed in the responses of the Baltic States, which all joined the euro area in the post-crisis period.

In sum, our findings confirm both asymmetric and diverse responses of existing member countries depending on which country is joining. But the "meteor shower" has a cooling down effect on volatility for highly interrelated markets such as the Baltic States or, as seen in the Slovenian case, with founding members in the pre-crisis period.

\section{Conclusions}

Although euro adoption is one of the most important events in European financial history, the euro adoption announcement and event effects are largely unexplored in the literature. Our paper is the first to examine the effects of both euro adoption news and the actual introduction of the euro in founding and non-founding members. Our results show that markets were discriminating in their responses, which were highly heterogeneous and dependent upon the country joining the euro and the country stock market of interest. In particular, the event study findings confirmed Green \& Bai's (2008) argument that the euro adoption was a well-known and scheduled event of the third stage of EMU, with low uncertainty about conditions of the euro accession. However, our results vary from this earlier work, as non-founding members, with less information on euro area effects, had substantial changes in their returns, albeit only in the pre-crisis period.

Heterogeneity also reared its head regarding asymmetric responses to euro introduction pre- and post-crisis, as the pre-crisis period showed the little-to-no response of local markets to the news on the adoption of the euro. In the post-crisis period, news of euro introduction had a strong impact in Lithuania, but the introduction of the euro had little effect (as hinted at by Alexakis et al., 2016), suggesting that the political worries surrounding the euro dissipated when financial markets saw the possible economic benefits.

Perhaps our most interesting result is that, with regard to spillover effects, founding members, in general, were undisturbed by additional euro introductions pre-crisis but actually saw decreased 
volatility in the post-crisis period from additional members (with the most financially open countries welcoming the euro's expansion the most). For the non-founding members, in general, there also was a reduction in volatility both in the pre-crisis and post-crisis periods. The "meteor shower" and "heat wave" hypotheses developed in Engle, et al. (1990) are useful in explaining our results, which confirm the asymmetric and diverse responses of existing member countries dependent upon which country is joining. However, as demonstrated, the "meteor shower" of the euro appeared to be a cool shower rather than a hot one, lessening volatility across borders.

The implications of this finding call for more investigation into the political economy of euro expansion; for example, the relief felt by the markets of founding members when new entrants joined in the post-crisis period could have been related to a renewed faith in the currency's viability (Hobolt $\&$ Wratil, 2015) and/or the relief felt by bringing in fairly stable member states who had been properly vetted and were already on the path of convergence (Franks, et al., 2018). Additional work in this vein, digging deeper into each specific case and especially the negotiations surrounding accession from the existing Member State side, might shed more light on how markets would have perceived the new members in the interim between the announcement of adoption and actual adoption. Econometrically this may encompass utilizing an alternative bivariate fractionally integrated APARCH-DCC modeling framework (Alexakis, et al., 2016) to study the directional impacts of euro area enlargement or perhaps even moving to a global vector regressive model which allows for the direct inclusion of trade and financial links and spillovers in a unified framework. In another direction, the dampened volatility in the new members may have been predicated on purely internal conditions and an anticipation effect from the euro's introduction (see Epstein \& Johnson [2010] for a disaggregation of some of these effects by country), while any subsequent crisis may change their response to additional entrants (again dependent upon the particulars of any new members). More carefully examining the internal conditions of both founding members and new entrants to the euro area to ascertain which was most important for driving market responses is also a natural extension to our work here.

In any event, this paper, by systematically exploring the reactions of markets to euro adoption, has made a modest contribution to understanding the dynamics of financial markets to the common currency. It is clear, however, that more work is called for in understanding the circumstances behind these responses. 


\section{References}

Adams, G., McQueen, G., \& Wood, R. (2004). The Effects of Inflation News on High Frequency Stock Returns. The Journal of Business, 77(3), 547-574.

Agénor, P. R. (2003). Benefits and costs of international financial integration: theory and facts. The World Economy, 26(8), 1089-1118.

Alexakis, P. D., Kenourgios, D., \& Dimitriou, D. (2016). On emerging stock market contagion: The Baltic region. Research in International Business and Finance, 36, 312-321.

Alexandrou, G., Koulakiotis, A., \& Dasilas, A. (2011). GARCH modelling of banking integration in the Eurozone. Research in International Business and Finance, 25(1), 1-10.

Andersen, T. G., Bollerslev, T., Diebold, F. X., \& Vega, C. (2007). Real-time price discovery in global stock, bond and foreign exchange markets. Journal of International Economics, 73(2), 251-277.

Avalos, H. R. (2016). Financial Crisis in the Euro-Zone and Moral Hazard. Journal of Finance and Accounting, 4(4), 164-178.

Backé, P., \& Dvorsky, S. (2018). Enlargement of the euro area toward CESEE: progress and perspectives. Focus on European Economic Integration(Q3-18), 43-56.

Badinger, H., \& Breuss, F. (2009). Country size and the trade effects of the euro. Review of World Economics, 145(2), 207-223.

Bae, K. H., \& Karolyi, G. A. (1994). Good news, bad news and international spillovers of stock return volatility between Japan and the US. Pacific-Basin Finance Journal, 2(4), 405-438.

Bartram, S. M., \& Karolyi, G. A. (2006). The Impact of the Introduction of the Euro on Foreign Exchange Rate Risk Exposures. Journal of Empirical Finance, 13(4-5), 519-549.

Bartram, S. M., Taylor, S. J., \& Wang, Y. H. (2007). The Euro and European financial market dependence. Journal of Banking \& Finance, 31(5), 1461-1481.

Baumeister, R. F., Bratslavsky, E., Finkenauer, C., \& Vohs, K. D. (2001). Bad is stronger than good. Review of General Psychology, 5(4), 323-370.

Bekaert, G., \& Wu, G. (2000). Asymmetric volatility and risk in equity markets. Review of Financial Studies, 13(1), 1-42.

Bekaert, G., Harvey, C. R., Lundblad, C. T., \& Siegel, S. (2013). The European Union, the Euro, and equity market integration. Journal of Financial Economics, 109(3), 583-603.

Bekaert, G., Harvey, C. R., Lundblad, C., \& Siegel, S. (2007). Global Growth Opportunities and Market Integration. The Journal of Finance, 62(3), 1081-1137.

Bhanot, K., Burns, N., Hunter, D., \& Williams, M. (2014). News spillovers from the Greek debt crisis: Impact on the Eurozone financial sector. Journal of Banking \& Finance, 38, 51-63.

Billio, M., \& Pelizzon, L. (2003). Volatility and shocks spillover before and after EMU in European stock markets. Journal of Multinational Financial Management, 13(4), 323-340.

Birz, G., \& Lott, J. R. (2011). The effect of macroeconomic news on stock returns: New evidence from newspaper coverage. Journal of Banking \& Finance, 35(11), 2791-2800.

Bollerslev, T. P. (1986). Generalized autoregressive conditional heteroskedasticity. Journal of Econometrics, 31, 307-327.

Bomfim, A. N. (2003). Pre-announcement effects, news effects, and volatility: Monetary policy and the stock market. Journal of Banking \& Finance, 27(1), 133-151.

Böwer, U., \& Guillemineau, C. (2006). Determinants of Business Cycle Synchronisation across Euro Area Countries. European Central Bank, Working Paper Series No 587.

Boyd, J. H., Hu, J., \& Jagannathan, R. (2005). The stock market's reaction to unemployment news: Why bad news is usually good for stocks. The Journal of Finance, 60(2), 649-672.

Brenner, M., Pasquariello, P., \& Subrahmanyam, M. (2009). On the volatility and comovement of U.S. financial markets around macroeconomic news announcements. Journal of Financial and Quantitative Analysis, 44(6), 1265-1289. 
Bris, A., Koskinen, Y., \& Nilsson, M. (2008). The Euro and Corporate Valuations. The Review of Financial Studies, 22(8), 3171-3209.

Campbell, J. Y., Lo, A. W., \& MacKinlay, A. C. (1997). The econometrics of financial markets. Princeton, N.J.: Princeton University Press.

Caporale, G. M., Spagnolo, F., \& Spagnolo, N. (2016). Macro news and stock returns in the Euro area: A VAR-GARCH-in-mean analysis. International Review of Financial Analysis, 45, 180-188.

Chandra, A., \& Thenmozhi, M. (2017). Behavioural Asset Pricing: Review and Synthesis. Journal of Interdisciplinary Economics, 29(1), 1-31.

Chen, N.-F., Roll, R., \& Ross, S. A. (1986). Economic Forces and the Stock Market. The Journal of Business, 59(3), 383-403.

Connolly, R. A., \& Wang, F. A. (1998). Economic news and stock market linkages: Evidence from the US, UK and Japan. Proceedings of the Second Joint Central Bank Research Conference on Risk Management and Systemic Risk, 1, pp. 211-240.

Connolly, R., \& Hartwell, C. A. (2014). Developments in the economies of member states outside the eurozone. Journal of Common Market Studies(52 (Annual Review)), 202-218.

Corredor, P., Ferrer, E., \& Santamaria, R. (2013). Investor sentiment effect in stock markets: Stock characteristics or country-specific factors? International Review of Economics \& Finance, 27, 572-591.

Cutler, D. M., Poterba, J. M., \& Summers, L. H. (1989). What Moves Stock Prices? The Journal of Portfolio Management, 15(3), 4-12.

Dimitriou, D., Kenourgios, D., \& Simos, T. (2013). Global financial crisis and emerging stock market contagion: A multivariate FIAPARCH-DCC approach. International Review of Financial Analysis, 30, 46-56.

Ding, Z. X., Engle, R. F., \& Granger, C. W. (1993). A long memory property of stock market returns and a new model. Journal of Empirical Finance, 1, 83-106.

Docking, D. S., \& Koch, P. D. (2005). Sensitivity of investor reaction to market direction and volatility: dividend change announcements. Journal of Financial Research, 28, 21-40.

Eiling, E., Gerard, B., \& de Roon, F. (2012). Euro-Zone Equity Returns: Country Versus Industry Effects. Review of Finance, 16(3), 755-798.

Engle, R. F., \& Ng, V. K. (1993). Measuring and testing the impact of news on volatility. The Journal of Finance, 48(5), 1749-1778.

Engle, R. F., Ito, T., \& Lin, W.-L. (1990). Meteor Showers or Heat Waves? Heteroskedastic IntraDaily Volatility in the Foreign Exchange Market. Econometrica, 58(3), 525-542.

Epstein, R. A., \& Johnson, J. (2010). Uneven Integration: Economic and Monetary Union in Central and Eastern Europe. JCMS: Journal of Common Market Studies, 48(5), 1237-1260.

Eurobarometer. (2007). Survey among enterprises in Slovenia - after the euro introduction. Brussels: European Commission.

Eurobarometer. (2014, September). Introduction of the euro in Lithuania. Retrieved from http://ec.europa.eu/commfrontoffice/publicopinion/flash/fl_402_en.pdf

Eurobarometer. (2015). Lithuania after the Euro Changeover. Brussels: European Commission.

Fahrolz, C., \& Mohl, P. (2003). Fiscal and Monetary Policy in Belgium, France, Germany, Luxembourg and the Netherlands. Ezoneplus Working paper No 17C. Retrieved from https://www.researchgate.net/publication/5021452_Fiscal_and_Monetary_Policy_in_Belgiu m_France_Germany_Luxembourg_and_The_Netherlands

Fedorova, E., \& Saleem, K. (2010). Volatility Spillovers between Stock and Currency Markets: Evidence from Emerging Eastern Europe. Czech Journal of Economics and Finance (Finance a uver), 60(6), 519-533.

Fernández-Rodríguez, F., Gómez-Puig, M., \& Sosvilla-Rivero, S. (2015). Volatility spillovers in EMU sovereign bond markets. International Review of Economics \& Finance, 39, 337-352. 
Flannery, M. J., \& Protopapadakis, A. A. (2002). Macroeconomic factors do influence aggregate stock returns. Review of Financial Studies, 3, 751-782.

Fomby, T., \& Murfin, J. (2005). Inconsistency of HAC standard errors in event studies with i.i.d. errors. Applied Financial Economic Letters, 1, 239-242.

Franks, M. J., Barkbu, M. B., Blavy, M. R., Oman, W., \& Schoelermann, H. (2018). Economic convergence in the euro area: coming together or drifting apart? Washington DC: International Monetary Fund.

Fratzscher, M. (2002). Financial market integration in Europe: on the effects of EMU on stock markets. International Journal of Finance \& Economics, 7(3), 165-193.

Garcia, D. (2013). Sentiment during recessions. The Journal of Finance, 68(3), 1267-1300.

Geweke, J. (1986). Modelling the Persistence of Conditional Variance: A Comment. Econometric Reviews, 5, 57-61.

Glosten, L. R., Jagannathan, R., \& Runkle, D. E. (1993). On the relation between the expected value and the volatility of the nominal excess return on stocks. Journal of Finance, 48(5), 17791801.

Green, C. J., \& Bai, Y. (2008). The euro: Did the markets cheer or jeer? Journal of Policy Modeling, $30(3), 431-446$.

Guardiancich, I. (2016). Slovenia: The end of a success story? When a partial reform equilibrium turns bad. Europe-Asia Studies, 68(2), 205-231.

Hamao, Y., Masulis, R., \& Ng, V. (1990). Correlations in price changes and volatility across international stock markets. Review of Financial Studies, 3, 281-307.

Hau, H. (2006). The role of transaction costs for financial volatility: Evidence from the Paris Bourse. Journal of the European Economic Association, 4(4), 862-890.

Hayo, B., \& Kutan, A. M. (2005). IMF-related news and emerging financial markets. Journal of International Money and Finance, 24(7), 1126-1142.

Hentschel, L. (1995). All in the family nesting symmetric and asymmetric GARCH models. Journal of Financial Economics, 39(1), 71-104.

Herrero, G., \& Ruiz, J. M. (2008). Do Trade and Financial Linkages Foster Business Cycle Synchronization in a Small Economy? Working Paper No 0810. Bank of Spain.

Ho, C., \& Hung, C.-H. (2009). Investor sentiment as conditioning information in asset pricing. Journal of Banking \& Finance, 33(5), 892-903.

Hobolt, S. B., \& Wratil, C. (2015). Public opinion and the crisis: the dynamics of support for the euro. Journal of European Public Policy, 22(2), 238-256.

Hochreiter, E., \& Tavlas, G. S. (2005). Two Roads to the Euro: The Monetary Experiences of Austria and Greece. In S. Schadler, Euro Adoption in Central and Eastern Europe: Opportunities and Challenges (pp. 187-201). Washington DC: International Monetary Fund.

Hodson, D. (2015). Eurozone Governance: Deflation, Grexit 2.0 and the Second Coming of JeanClaude Juncker. JCMS: Journal of Common Market Studies, 1(53), 144-161.

Holler, J. (2012). Event Study-Methodik und statistische Signifikanz. OIWIR Verlag für Wirtschaft, Informatik und Recht.

Hurník, J., Tuma, Z., \& Vávra, D. (2010). The Euro Adoption Debate Revisited: The Czech Case. Czech Journal of Economics and Finance (Finance a uver), 60(3), 194-212.

Jiang, G. J., Konstantinidi, E., \& Skiadopoulos, G. (2012). Volatility spillovers and the effect of news announcements. Journal of Banking \& Finance, 36(8), 2260-2273.

Jones, C., Lamont, O., \& Lumsdaine, R. (1998). Macroeconomic news and bond market volatility. Journal of Financial Economics, 47, 315-337.

Karafiath, I. (1988). Using Dummy Variables in the Event Methodology. The Financial Review, 23(3), 351-357.

Kim, S. J., Moshirian, F., \& Wu, E. (2005). Dynamic stock market integration driven by the European Monetary Union: An empirical analysis. Journal of Banking \& Finance, 29(10), 2475-2502. 
Kim, S. J., Salem, L., \& Wu, E. (2015). The role of macroeconomic news in sovereign CDS markets: Domestic and spillover news effects from the US, the Eurozone and China. Journal of Financial Stability, 18, 208-224.

Kiohos, A., \& Stoupos, N. (2018). Re-Exploring the Enlargement of the Eurozone: Evidence from the New Member-States. International Economic Journal, 32(2), 177-198.

Kliber, A., \& Płuciennik, P. (2017). Euro or not? Vulnerability of Czech and Slovak economies to regional and international turmoil. Economic Modelling, 60, 313-323.

Knif, J., Kolari, J., \& Pynnönen, S. (2008). tock market reaction to good and bad inflation news. Journal of Financial Research, 31(2), 141-166.

Kohonen, A. (2013). On detection of volatility spillovers in overlapping stock markets. Journal of Empirical Finance, 22, 140-158.

Koliastasis, P. (2015). The Greek Parliamentary Elections of 25 January, 2015. Representation, 51(3), 359-372.

Koulakiotis, A., Kiohos, A., \& Papasyriopoulos, N. (2016). Transmission of News in Eurozone Bank Holdings and European Bank Markets in the Light of the Greek Debt Crisis. Journal of Emerging Market Finance, 15(1), 1-48.

Kozamernik, D. (2004). The ERM II issues: An interpretation of the Slovenian approach. Atlantic Economic Journal, 32(4), 268-279.

Kyriacou, G. A. (2006). The introduction of the euro in Cyprus: challenges and prospects. Retrieved from http://www.centralbank.gov.cy/media/pdf/spee_georgekyriacou_221106_.pdf

Lemmon, M., \& Portniaguina, E. (2006). Consumer Confidence and Asset Prices: Some Empirical Evidence. The Review of Financial Studies, 19(4), 1499-1529.

Levasseur, S. (2015, January 5). The official introduction of the euro in Lithuania: does it really make no difference? Retrieved from https://www.ofce.sciences-po.fr/blog/official-introductioneuro-lithuania-no-difference-really/

Li, L., \& Engle, R. F. (1998). Macroeconomic announcements and volatility of treasury futures. Department of Economics Discussion paper 98-27. San Diego: University of California.

Lomas, U. (2007, November 29). Cyprus And Malta Well Prepared for Euro Adoption. Retrieved from https://www.tax-

news.com/news/Cyprus_And_Malta_Well_Prepared_For_Euro_Adoption 29156.html

Lucchetti, K., \& Balietti, S. (2011). The gig package, Version 2.2.

MacKinlay, A. C. (1997). Journal of Economic Literature. Event Studies in Economics and Finance, 35(1), 13-39.

Markevičiūtè, A., \& Kuokštis, V. (2016). Race to the Euro: Why Latvia Joined Earlier Than Lithuania. Baltic Journal of Political Science, 5(5), 5-20.

McQueen, G., \& Roley, V. V. (1993). Stock prices, news, and business conditions. Review of Financial Studies, 6(3), 683-707.

McQueen, G., \& Roley, V. V. (1993). Stock Prices, News, and Business Conditions. Review of Financial Studies, 6(3), 683-707.

Mitchell, M. L., \& Mulherin, J. H. (1994). The impact of public information on the stock market. The Journal of Finance, 49(3), 923-950.

Mongelli, F. P., \& Wyplosz, C. (2008). The Euro at Ten - Unfulfilled Threats and Unexpected Challenges. In B. Maćkowiak, F. P. Mongelli, G. Noblet, \& F. Smets, Fifth ECB Central Banking Conference: The Euro at Ten - Lessons and Challenges (pp. 24-57). Frankfurt: European Central Bank.

Morana, C., \& Beltratti, A. (2002). The effects of the introduction of the euro on the volatility of European stock markets. Journal of Banking \& Finance, 26(10), 2047-2064.

Mundell, R. A. (1998). What the euro means for the dollar and the international monetary system. Atlantic Economic Journal, 26(3), 227-237. 
Murtagh, F., \& Legendre, P. (2014). Ward's hierarchical agglomerative clustering method: which algorithms implement Ward's criterion? Journal of Classification, 31, 274-295.

Nelson, D. (1991). Conditional heteroskedasticity in asset returns: a new approach. Econometrica, 59, 347-370.

Nikkinen, J., \& Sahlström, P. (2004). Scheduled domestic and US macroeconomic news and stock valuation in Europe. Journal of Multinational Financial Management, 14(3), 201-215.

Nikkinen, J., Omran, M., Sahlström, P., \& Äijö, J. (2006). Global stock market reactions to scheduled US macroeconomic news announcements. Global Finance Journal, 17(1), 92-104.

Ottaviano, G. I., Taglioni, D., \& Di Mauro, F. (2009). The euro and the competitiveness of European firms. Economic Policy, 24(57), 6-53.

Pantula, S. (1986). Modelling the Persistence of Conditional Variance: A Comment. Econometric Reviews, 5, 71-73.

Paresh, K. N., \& Sharma, S. S. (2015). Does data frequency matter for the impact of forward premium on spot exchange rate? International Review of Financial Analysis, 39, 45-53.

Pechova, A. (2012). Legitimising discourses in the framework of European integration: The politics of Euro adoption in the Czech Republic and Slovakia. Review of International Political Economy, 19(5), 779-807.

Rangel, J. G. (2011). Macroeconomic news, announcements, and stock market jump intensity dynamics. Journal of Banking \& Finance, 35(5), 1263-1276.

Ribeiro, P. P., Cermeño, R., \& Curto, J. D. (2017). Sovereign bond markets and financial volatility dynamics: Panel-GARCH evidence for six euro area countries. Finance Research Letters, 21 , 107-114.

Schukkink, M., \& Niemann, A. (2012). Portugal and the EU's Eastern Enlargement: A logic of identity endorsement. European Integration online Papers (EIoP), 16(12). Retrieved from http://eiop.or.at/eiop/texte/2012-012a.htm

Sørensen, B. E., \& Yosha, O. (1998). International risk sharing and European monetary unification. Journal of International Economics, 45(2), 211-238.

Tse, Y. K. (1998). The Conditional Heteroscedasticity of the Yen-Dollar Exchange Rate. Journal of Applied Econometrics, 13, 49-55.

Van Eden, H., De Groot, A., Ledrut, E., Romijn, G., \& De Souza, L. (2000). EMU and enlargement: A review of policy issues. European Parliament Directorate-General for Research, Working Paper Econ No 117.

Veronesi, P. (1999). Stock market overreactions to bad news in good times: a rational expectations equilibrium model. Review of Financial Studies, 12(5), 975-1007.

Zakoian, J. M. (1994). Threshold heteroskedastic models. Journal of Economic Dynamic and Control, 18, 931-955. 
Table 1: Founding members' market reaction to the euro introduction related events

\begin{tabular}{|c|c|c|c|c|c|c|c|c|c|}
\hline \multicolumn{10}{|c|}{ Panel A: First announcement, 17.06.1997 } \\
\hline Country & Intercept & $\begin{array}{l}\text { Market } \\
\text { returns }\end{array}$ & $\begin{array}{c}\text { Significant } \\
\text { abnormal } \\
\text { returns at lags } \\
(+/-) \\
\end{array}$ & $\begin{array}{l}\text { CAR, } 1 \\
\text { month }\end{array}$ & $\begin{array}{c}\text { p- } \\
\text { value }\end{array}$ & $\begin{array}{l}\text { CAR, } 2 \\
\text { months }\end{array}$ & $\begin{array}{c}\text { p- } \\
\text { value }\end{array}$ & $\underset{\mathbf{R}^{2}}{\text { Adj. }}$ & $\mathbf{n}$ \\
\hline AT & -0.0003 & $0.48 * * *$ & $\begin{array}{c}\mathbf{9}, \mathbf{1 1}, \mathbf{2 2}, 24, \mathbf{2 6} \\
28,38\end{array}$ & 0.029 & 0.22 & $0.057 * * *$ & 0.01 & 0.39 & 291 \\
\hline $\mathrm{BE}$ & 0.0002 & $0.63 * * *$ & $\begin{array}{c}\mathbf{9}, \mathbf{1 1}, 13,31,33, \\
34,38\end{array}$ & $0.002 *$ & 0.06 & $-0.051 * * *$ & 0.00 & 0.54 & 293 \\
\hline $\mathrm{DE}$ & -0.0001 & $0.98 * * *$ & $\mathbf{9}, \mathbf{1 9}, \mathbf{2 6}, 28,34,36$ & 0.021 & 0.16 & $0.032 * *$ & 0.02 & 0.70 & 295 \\
\hline ES & 0.0003 & $0.83 * * *$ & $\mathbf{1 1}, 22,23,26,27$ & 0.020 & 0.69 & $-0.049 * * *$ & 0.00 & 0.52 & 292 \\
\hline FI & 0.0004 & $0.87 * * *$ & 27,34 & 0.022 & 0.89 & 0.055 & 0.33 & 0.45 & 293 \\
\hline FR & -0.0000 & $0.99 * * *$ & 6,11 & -0.021 & 0.40 & -0.063 & 0.65 & 0.60 & 294 \\
\hline $\mathrm{IE}$ & 0.0005 & $0.50 * * *$ & 32,38 & 0.000 & 0.61 & 0.039 & 0.23 & 0.36 & 295 \\
\hline NL & 0.0002 & $1.10 * * *$ & $22,31,39$ & 0.022 & 0.96 & -0.004 & 0.27 & 0.70 & 295 \\
\hline $\mathrm{PT}$ & $0.0011 * * *$ & $0.38 * * *$ & $\mathbf{1 1}, \mathbf{1 2}, \mathbf{1 4}, 17,37$ & $0.015^{* *}$ & 0.03 & 0.037 & 0.17 & 0.17 & 282 \\
\hline \multicolumn{10}{|c|}{ Panel B: Second announcement, 05.03.1998 } \\
\hline $\mathrm{AT}$ & -0.0004 & $0.73 * * *$ & $\mathbf{1 6}, \mathbf{3 3 - 3 5}, 38,39$ & 0.014 & 0.83 & $0.046 * *$ & 0.03 & 0.52 & 288 \\
\hline $\mathrm{BE}$ & -0.0002 & $0.73 * * *$ & 24 & 0.022 & 0.99 & 0.053 & 0.81 & 0.66 & 290 \\
\hline $\mathrm{DE}$ & 0.0001 & $1.06 * * *$ & 23, 31, 38,39, 40 & -0.016 & 0.91 & $-0.046 * * *$ & 0.00 & 0.75 & 290 \\
\hline ES & 0.0005 & $0.80 * * *$ & $\mathbf{1 1}, 29,35$ & 0.054 & 0.81 & 0.021 & 0.35 & 0.65 & 286 \\
\hline FI & 0.0005 & $0.97 * * *$ & $11,13, \mathbf{2 9}, \mathbf{3 6}$ & -0.023 & 0.28 & $0.050^{*}$ & 0.08 & 0.64 & 289 \\
\hline FR & -0.0003 & $0.95 * * *$ & 18,40 & 0.048 & 0.46 & 0.058 & 0.63 & 0.70 & 291 \\
\hline IE & $0.0014 * * *$ & $0.46^{* * *}$ & $0, \mathbf{9}, 18,24,38$ & -0.011 & 0.14 & $-0.046^{* *}$ & 0.03 & 0.43 & 290 \\
\hline NL & 0.0001 & $1.07 * * *$ & $\mathbf{3 6}, 38$ & -0.036 & 0.93 & -0.013 & 0.66 & 0.79 & 291 \\
\hline $\mathrm{PT}$ & $0.0013 * * *$ & $0.61 * * *$ & 36,38 & 0.035 & 0.96 & 0.038 & 0.59 & 0.45 & 282 \\
\hline \multicolumn{10}{|c|}{ Panel C: Euro introduction event, 01.01.1999 } \\
\hline AT & -0.0012 & $0.67 * * *$ & $9, \mathbf{1 6}, \mathbf{2 3}, \mathbf{2 6}, \mathbf{3 1}$ & -0.021 & 0.11 & $0.093 * *$ & 0.02 & 0.51 & 289 \\
\hline $\mathrm{BE}$ & 0.0006 & $0.61 * * *$ & $2,9,27,37$ & $-0.085 * * *$ & 0.00 & $-0.105 * * *$ & 0.00 & 0.66 & 292 \\
\hline $\mathrm{DE}$ & -0.0006 & $0.93 * * *$ & $4,27,34$ & 0.003 & 0.35 & -0.006 & 0.47 & 0.74 & 293 \\
\hline ES & 0.0005 & $0.94 * * *$ & $7,22,26,27,32,33$ & -0.061 & 0.34 & $-0.032 *$ & 0.08 & 0.79 & 287 \\
\hline FI & 0.0008 & $0.99 * * *$ & $\mathbf{3}, \mathbf{4}, 24$ & 0.038 & 0.26 & 0.052 & 0.27 & 0.64 & 290 \\
\hline FR & 0.0004 & $0.94 * * *$ & $6,29,34,39$ & 0.004 & 0.60 & -0.027 & 0.49 & 0.87 & 290 \\
\hline $\mathrm{IE}$ & 0.0001 & $0.52 * * *$ & 2,21 & 0.003 & 0.61 & 0.054 & 0.45 & 0.33 & 289 \\
\hline IT & -0.0002 & $1.04 * * *$ & $\mathbf{3}, 11, \mathbf{2 7}, 36$ & -0.021 & 0.29 & 0.014 & 0.24 & 0.74 & 290 \\
\hline NL & 0.0001 & $0.95 * * *$ & $3,12,19, \mathbf{2 6}, 33$ & $-0.062 * * *$ & 0.00 & $-0.052 * * *$ & 0.01 & 0.85 & 293 \\
\hline PT & -0.0001 & $0.81 * * *$ & & 0.005 & 0.84 & 0.019 & 0.94 & 0.53 & 287 \\
\hline
\end{tabular}

Significance levels: * $10 \%, * * 5 \%, * * * 1 \%$

Notes: significant lags denote at least at $5 \%$ level significant abnormal returns with positive values marked in bold. CAR stands for cumulative abnormal returns, where 1 month is tested after 20 trading days and 2 months after 40 trading days. Columns for $\mathrm{p}$-value are used to test the joint significance of dummy variables by a corresponding F-test for omitted variables up to 1 trading month and 2 trading months. Due to the missing observations, Italy and Luxembourg are not presented in Panel A and B; Luxembourg is also excluded from euro introduction Panel C. 
Table 2: Non-Founding members' market reactions to the euro adoption announcement and the euro adoption events

\begin{tabular}{|c|c|c|c|c|c|c|c|c|c|c|}
\hline \multicolumn{11}{|c|}{ Panel A: Euro adoption announcement } \\
\hline Country & Date & Intercept & $\begin{array}{l}\text { Market } \\
\text { returns }\end{array}$ & \begin{tabular}{|c|}
$\begin{array}{c}\text { Significant } \\
\text { abnormal } \\
\text { returns at } \\
\text { lags }(+/-)\end{array}$ \\
\end{tabular} & $\begin{array}{l}\text { CAR, } 1 \\
\text { month }\end{array}$ & $\begin{array}{c}p- \\
\text { value }\end{array}$ & $\begin{array}{l}\text { CAR, } 2 \\
\text { months }\end{array}$ & $\begin{array}{c}p- \\
\text { value }\end{array}$ & $\begin{array}{c}\text { Adj. } \\
\mathbf{R}^{\mathbf{2}}\end{array}$ & $\mathbf{n}$ \\
\hline GR & 20.06 .2000 & -0.0005 & $0.29 * * *$ & - & -0.041 & 1.00 & -0.079 & 1.00 & -0.07 & 293 \\
\hline SI & 02.03 .2006 & 0.0003 & -0.01 & - & -0.016 & 1.00 & -0.043 & 1.00 & -0.11 & 278 \\
\hline $\mathrm{CY}$ & 16.05 .2007 & $0.0018 * *$ & $0.55 * * *$ & $\mathbf{0}$ & -0.012 & 1.00 & -0.012 & 0.98 & 0.01 & 288 \\
\hline MT & 16.05 .2007 & -0.0001 & 0.02 & - & -0.014 & 1.00 & 0.004 & 0.97 & -0.09 & 283 \\
\hline SK & 07.05 .2008 & -0.0001 & 0.18 & - & -0.021 & 0.43 & -0.045 & 0.40 & 0.01 & 76 \\
\hline $\mathrm{EE}$ & 03.07 .2010 & $0.0021 * *$ & $0.18 * * *$ & 7,24 & -0.024 & 0.82 & 0.003 & 0.86 & 0.00 & 295 \\
\hline $\mathrm{LV}$ & 09.07 .2013 & $0.0008^{*}$ & $0.08 * *$ & $\mathbf{5}, 32,40$ & 0.054 & 0.22 & 0.022 & 0.32 & 0.03 & 291 \\
\hline LT & 23.07 .2014 & 0.0003 & $0.14 * * *$ & 11,12 & $-0.048 * * *$ & 0.00 & $-0.051 *$ & 0.09 & 0.10 & 291 \\
\hline \multicolumn{11}{|c|}{ Panel B: Euro adoption event } \\
\hline GR & 01.01 .2001 & -0.0014 & $0.28 * * *$ & \begin{tabular}{|l|}
7,21 \\
\end{tabular} & 0.018 & 0.28 & 0.087 & 0.69 & 0.03 & 291 \\
\hline SI & 01.01 .2007 & $0.0012 * * *$ & 0.00 & $\begin{array}{c}\mathbf{1}, \mathbf{2}, 11, \mathbf{1 6} \\
\mathbf{2 0}, 35\end{array}$ & $0.093 * * *$ & 0.00 & $0.063 * * *$ & 0.00 & 0.11 & 284 \\
\hline $\mathrm{CY}$ & 01.01 .2008 & 0.0004 & $0.76 * * *$ & $\begin{array}{l}1,6,7,10 \\
\mathbf{1 6}, \mathbf{1 7}, 21\end{array}$ & $-0.040 * * *$ & 0.00 & $-0.100 * * *$ & 0.00 & 0.41 & 280 \\
\hline MT & 01.01 .2008 & -0.0000 & $0.08 * *$ & $\begin{array}{c}2,12,16,21 \\
34,35,36\end{array}$ & $-0.014 * * *$ & 0.00 & -0.040 & 0.15 & 0.17 & 269 \\
\hline SK & 01.01 .2009 & -0.0050 & 0.03 & - & 0.008 & 1.00 & -0.032 & 1.00 & -0.14 & 62 \\
\hline $\mathrm{EE}$ & 01.01 .2011 & $0.0018 * *$ & $0.30 * * *$ & 3 & 0.007 & 0.65 & -0.020 & 0.99 & 0.01 & 292 \\
\hline $\mathrm{LV}$ & 01.01 .2014 & 0.0007 & 0.05 & 13 & 0.016 & 0.76 & -0.003 & 0.98 & -0.06 & 287 \\
\hline $\mathrm{LT}$ & 01.01 .2015 & 0.0002 & $0.08 * *$ & $17, \mathbf{1 9}, \mathbf{2 4}$ & 0.011 & 0.56 & 0.032 & 0.54 & -0.02 & 291 \\
\hline \multicolumn{11}{|c|}{ Panel C: Failed to meet convergence criteria } \\
\hline GR & 05.03 .1998 & 0.0011 & 0.1424 & $\mathbf{0}, \mathbf{1}, 5, \mathbf{1 6}, 17$ & $0.0828 * * *$ & 0.01 & $0.1062 * * * *$ & 0.00 & 0.21 & 292 \\
\hline LT & 16.05 .2006 & 0.0001 & 0.0138 & $5,11,20,23,27$ & $-0.1089 * * *$ & 0.00 & $-0.0714 * *$ & 0.01 & 0.09 & 249 \\
\hline
\end{tabular}

Significance levels: * $10 \%, * * 5 \%, * * * 1 \%$

Notes: see Table 1. 
Table 3: Unrestricted APARCH $(1,1)$ models and restricted model selection

\begin{tabular}{|c|c|c|c|c|c|c|c|}
\hline \multicolumn{8}{|c|}{ Panel A: Founding members } \\
\hline Country & Intercept, $\omega$ & Power, $\delta$ (st. err.) & Asymmetry, $\gamma$ & $\boldsymbol{\alpha}$ & $\beta$ & Restricted model & $\mathbf{n}$ \\
\hline $\mathrm{AT}$ & $3.37 * *$ & $1.65(2.49)$ & $0.97 * *$ & 0.09 & $0.56 * * *$ & GJR & 230 \\
\hline $\mathrm{BE}$ & $1.92 * * *$ & $1.28(0.92)$ & $0.53 * *$ & $0.32 * * *$ & $0.49 * * *$ & TARCH & 230 \\
\hline $\mathrm{DE}$ & 0.09 & $1.80(1.11)$ & -0.18 & $0.11 * * *$ & $0.88 * * *$ & GARCH & 230 \\
\hline ES & $0.56 * *$ & $0.64(1.45)$ & 0.48 & 0.11 & $0.85 * * *$ & TS-GARCH & 230 \\
\hline FI & 0.18 & $2.22(0.73)$ & -0.04 & $0.15 * * *$ & $0.84 * * *$ & GARCH & 230 \\
\hline FR & 0.06 & $2.17(2.47)$ & 0.03 & 0.08 & $0.86 * * *$ & GARCH & 230 \\
\hline $\mathrm{IE}$ & 1.00 & $3.07(11.43)$ & 0.09 & 0.13 & $0.74 * * *$ & GARCH & 222 \\
\hline IT & 0.61 & $0.90(0.89)$ & -0.16 & $0.17 * * *$ & $0.79 * * *$ & TS-GARCH & 207 \\
\hline LU & $3.03 * *$ & $0.47(0.49)$ & 0.05 & $0.28 * * *$ & $0.61 * * *$ & TS-GARCH & 194 \\
\hline NL & 0.33 & $0.37(0.51)$ & -0.10 & $0.14 * *$ & $0.83 * * *$ & TS-GARCH & 230 \\
\hline $\mathrm{PT}$ & 1.89 & $2.26(3.27)$ & -0.04 & 0.12 & $0.75 * * *$ & GARCH & 230 \\
\hline \multicolumn{8}{|c|}{ Panel B: Non-founding members } \\
\hline GR & $2.86^{*}$ & $0.74(0.51)$ & $0.35 *$ & $0.17 * *$ & $0.81 * * *$ & TARCH & 230 \\
\hline SI & 0.70 & $0.41(0.51)$ & -0.21 & $0.13 * *$ & $0.86 * * *$ & TS-GARCH & 177 \\
\hline $\mathrm{CY}$ & 9.39 & $1.20(0.89)$ & $0.99 * *$ & $0.06^{*}$ & $0.87 * * *$ & TARCH & 126 \\
\hline MT & $4.33 * * *$ & $1.13(0.78)$ & $-0.53 * *$ & $0.25 * * *$ & $0.58 * * *$ & TARCH & 230 \\
\hline EE & 1.72 & $0.23(0.49)$ & -0.26 & $0.19 * *$ & $0.81 * * *$ & TS-GARCH & 222 \\
\hline $\mathrm{LV}$ & 1.70 & $0.32(0.42)$ & -0.31 & $0.16^{* * *}$ & $0.83 * * *$ & TS-GARCH & 182 \\
\hline LT & 0.90 & $1.50(0.76)$ & -0.01 & $0.19 * * *$ & $0.81 * * *$ & GARCH & 182 \\
\hline
\end{tabular}

Significance levels: * $10 \%, * * 5 \%, * * * 1 \%$

Notes: Slovakia has no continuous monthly data and is removed from our further analysis. Seeking to stabilize the convergence of the estimation algorithm, all variables, except dummy variables, where transformed multiplying by a factor of 100 . 
Table 4: Founding members' market reaction to euro adoption announcement and the euro adoption event, conditional mean equation

\begin{tabular}{|c|c|c|c|c|c|c|c|c|c|c|c|}
\hline Country & AT & BE & DE & ES & FI & FR & IE & IT & $\mathbf{L U}$ & NL & PT \\
\hline \multicolumn{12}{|c|}{ Panel A: euro announcement events } \\
\hline D1news & -2.85 & 0.14 & -2.08 & 2.04 & -2.77 & $2.80 * *$ & -3.19 & -- & -- & 0.98 & 2.91 \\
\hline D2news & -0.38 & $3.24^{+}$ & -2.28 & $4.69^{+}$ & -4.65 & $3.68 * * *$ & -2.56 & $10 * * *$ & -- & $-3.16^{+}$ & $7.04 *$ \\
\hline Dnews.gr & 0.96 & $3.65^{+}$ & -2.06 & -0.07 & -2.90 & $1.41^{+}$ & 1.21 & $4.16^{+}$ & $7.19^{+}$ & $3.35^{+}$ & 2.64 \\
\hline Dnews.si & -0.12 & 0.06 & -1.20 & $4.38^{+}$ & 1.23 & -0.94 & 2.42 & 1.32 & -0.47 & -0.41 & $7.23^{*}$ \\
\hline Dnews.mt.cy & 0.24 & -0.34 & $2.39^{+}$ & $4.12^{+}$ & 2.74 & -0.10 & 1.20 & -2.93 & 1.71 & -0.96 & $6.48^{+}$ \\
\hline Dnews.sk & $6.62^{+}$ & $-6.50 * *$ & 0.02 & -1.58 & 1.46 & -1.00 & $-14 * * *$ & $-4.82^{+}$ & $-7.19 * *$ & $-6.50 * * *$ & $-5.79^{+}$ \\
\hline Dnews.ee & 1.61 & -1.71 & 0.96 & -0.89 & 0.94 & -0.23 & $5.17^{+}$ & 1.10 & 1.09 & 1.13 & 2.23 \\
\hline Dnews.lv & -1.60 & -1.08 & -0.97 & $5.49 *$ & 2.55 & -0.43 & $-4.32^{+}$ & -1.64 & -4.24 & $-2.84^{+}$ & -1.25 \\
\hline Dnews.lt & $-4.94^{+}$ & 2.02 & -0.84 & -0.05 & 4.18 & -0.66 & 0.86 & -0.24 & 3.07 & 1.34 & $-11^{* * * *}$ \\
\hline \multicolumn{12}{|c|}{ Panel B: euro introduction events } \\
\hline Deuro & $-7.80^{+}$ & $-5.23 *$ & $-4.04^{+}$ & $-4.76^{+}$ & 0.95 & $2.63 * *$ & -2.14 & -1.18 & -- & $-6.02 * *$ & 2.75 \\
\hline Deuro.gr & 3.24 & 0.27 & $5.39 * *$ & $7.19 * *$ & $-19 * * *$ & $1.31^{+}$ & 1.68 & $3.51^{+}$ & $6.96^{+}$ & 1.55 & $8.95 * *$ \\
\hline Deuro.si & 0.19 & -0.02 & 0.45 & 1.63 & 3.52 & 0.04 & -2.09 & -0.20 & 2.38 & -0.60 & 1.29 \\
\hline Deu & $-5.53^{+}$ & 0.27 & -1.43 & -0.25 & 3.66 & -0.23 & $7.04 *$ & $4.33^{+}$ & -0.49 & -1.36 & -3.29 \\
\hline Deuro.sk & $6.35^{+}$ & $5.96^{*}$ & 1.18 & -1.28 & 2.35 & 0.44 & $8.09 *$ & 0.17 & 3.20 & $10.72 * * *$ & $6.56^{+}$ \\
\hline Deuro.ee & $-5.53^{+}$ & -1.30 & $-4.17 *$ & $4.46^{+}$ & -3.72 & 0.12 & $-6.13^{+}$ & $2.93^{+}$ & $-10.99 * *$ & $-4.06^{*}$ & -0.78 \\
\hline Deuro.lv & 2.08 & 1.00 & 0.46 & 2.35 & -1.02 & 0.08 & $4.31^{+}$ & $6.07 * *$ & 1.27 & -1.03 & 2.67 \\
\hline Deuro.lt & -3.37 & $3.63^{+}$ & 1.97 & $-5.95^{*}$ & 0.49 & $2.04^{+}$ & -0.89 & 1.27 & -1.26 & -0.27 & -0.86 \\
\hline \multicolumn{12}{|c|}{ Panel C: control variables } \\
\hline Intercept & 0.49 & $0.56^{*}$ & $0.29^{+}$ & 0.09 & -0.56 & -0.03 & -0.29 & -0.02 & 0.35 & 0.18 & 0.19 \\
\hline $\begin{array}{l}\text { Market } \\
\text { spillover }\end{array}$ & $0.68 * * *$ & $0.68 * * *$ & $1.07 * * *$ & $0.89 * * *$ & $1.07 * * *$ & $0.93 * * *$ & $0.70 * * *$ & $0.99 * * *$ & $0.89^{* * *}$ & $0.96^{* * *}$ & $0.79 * * *$ \\
\hline ESI, EA & 0.04 & 0.03 & $-0.31^{+}$ & $0.64 *$ & 0.39 & $0.30 * *$ & 0.08 & 0.21 & 0.36 & 0.09 & $0.87 *$ \\
\hline ESI, EU & 0.48 & 0.18 & $0.27^{+}$ & $-0.64 *$ & -0.29 & $-0.19^{+}$ & 0.28 & -0.10 & 0.15 & 0.02 & $-0.61^{+}$ \\
\hline M1 & -0.25 & $-0.8 * * *$ & -0.08 & 0.12 & 1.04 & -0.02 & 0.52 & $-0.48^{*}$ & -0.22 & -0.21 & -0.37 \\
\hline \multicolumn{12}{|c|}{ Country-level controls } \\
\hline ESI & $0.14^{+}$ & $0.20^{*}$ & 0.03 & 0.02 & 0.06 & 0.00 & -- & $0.19^{*}$ & -0.00 & $0.12^{+}$ & -0.07 \\
\hline $\begin{array}{l}\text { Industrial } \\
\text { production }\end{array}$ & -0.03 & -- & 0.12 & $-0.19^{+}$ & $-0.21^{+}$ & -0.02 & -0.01 & $-0.36 * *$ & 0.06 & -- & -- \\
\hline Unemployment & 0.01 & 0.02 & $-0.03 *$ & -0.01 & -0.03 & -0.00 & $-0.03 * *$ & -0.00 & -0.00 & 0.00 & 0.01 \\
\hline Inflation & -0.19 & 0.07 & 0.03 & -0.26 & 0.76 & $0.39^{+}$ & 0.26 & -0.12 & 0.01 & $-0.40^{+}$ & $-1.6 * *$ \\
\hline
\end{tabular}

High negative

Neutral

High positive

Significance levels: $* 10 \%, * * 5 \%, * * * 1 \%$

Notes: for the correct inference of estimated dummy variables parameters, we estimate the system without robust correction of the corresponding standard errors. To distinguish between highly insignificant parameter estimates and estimates for which t-ratios are higher than 1 , we denote the corresponding estimated parameters with ${ }^{+}$that corresponds to $32 \%$ significance level. The dummy for Slovakia coincides with the global financial crisis, hence the euro corresponding events and crisis event could not be separated. For controls with many missing observations, parameters are denoted with --. For notations of dummy variables see Appendix 1. 
Table 5: Founding members' market reaction to euro adoption announcement and the euro adoption event, conditional variance equation

\begin{tabular}{|c|c|c|c|c|c|c|c|c|c|c|c|}
\hline Country & AT & BE & DE & $\mathbf{E S}$ & FI & FR & IE & IT & $\mathbf{L U}$ & NL & PT \\
\hline \multicolumn{12}{|c|}{ Panel A: euro announcement events } \\
\hline D1news & -6.30 & -1.38 & 0.27 & $4.89^{+}$ & 0.98 & -0.05 & -3.05 & & & -0.57 & 2.86 \\
\hline D2news & 1.71 & 0.78 & 0.61 & 1.13 & 1.05 & $0.58 *$ & $10.66^{+}$ & & & -0.99 & $8.47 *$ \\
\hline Dnews.si & $-9.89^{+}$ & $-3.64 * *$ & $-1.47^{+}$ & -1.88 & -5.19 & -0.28 & $-7.8 * * *$ & -2.03 & $-8.58 *$ & $-3.99 * *$ & -2.34 \\
\hline Dnews.mt.cy & -7.87 & -1.83 & 0.05 & -0.82 & 6.67 & -0.01 & 13.49 & 0.09 & -5.54 & 2.32 & 1.98 \\
\hline Dnews.sk & 37.67 & 1.49 & -0.13 & 0.78 & 2.93 & 0.91 & $25.17^{+}$ & -2.04 & $31.43^{*}$ & 9.72 & 3.75 \\
\hline Dnews.lv & $-11.89 * *$ & -2.22 & -0.41 & $-4.60 * *$ & -5.20 & 0.34 & -2.55 & -0.52 & -7.01 & $-3.75 * * *$ & -4.74 \\
\hline Dnews.lt & -8.45 & $-3.50^{+}$ & -0.32 & -2.15 & $-4.27 * *$ & -0.52 & -10.02 & -2.17 & -7.16 & $-2.81 * * *$ & -0.17 \\
\hline \multicolumn{12}{|c|}{ Panel B: euro introduction events } \\
\hline Deuro & 6.58 & 2.16 & -0.10 & 0.06 & 1.35 & -0.25 & 3.60 & 1.40 & & -0.58 & 1.04 \\
\hline Deuro.gr & $31.42^{+}$ & $13.77^{+}$ & -0.10 & -2.42 & 4.37 & -0.33 & 1.41 & -1.32 & 4.69 & 2.44 & -1.90 \\
\hline Deuro.si & $-8.87^{+}$ & $-2.74^{+}$ & $-1.30 * *$ & $5.11^{+}$ & -3.40 & $-0.84 * *$ & 3.16 & $-4.26 * *$ & $-6.92 *$ & -1.27 & $-8.70 *$ \\
\hline Deuro.lv & $-12.92^{+}$ & -1.53 & -0.46 & $-2.99 *$ & $-5.42^{+}$ & -0.10 & 13.55 & -0.25 & $-8.70 * *$ & $-2.34 * *$ & 6.31 \\
\hline Deuro.lt & 6.48 & $-2.90 *$ & $-0.20^{+}$ & $-4.18 *$ & -1.74 & -0.44 & -4.13 & -1.82 & -6.36 & -1.77 & -2.99 \\
\hline \multicolumn{12}{|c|}{ Panel C: conditional variance variables } \\
\hline Constant & $8.16^{*}$ & $2.30 * * *$ & 0.11 & 0.88 & 0.65 & 0.08 & 0.82 & 0.44 & $2.64 * * *$ & $0.68 * *$ & 0.91 \\
\hline$\gamma$ & $0.98^{+}$ & $1.37 * *$ & & & & & & & & & \\
\hline$\alpha$ & 0.04 & $0.15^{* *}$ & $0.04^{+}$ & $0.11 * *$ & $0.09 * *$ & 0.04 & 0.05 & $0.10^{*}$ & $0.27 * * *$ & 0.04 & 0.00 \\
\hline$\beta$ & $0.41 *$ & $0.58 * * *$ & $0.92 * * *$ & $0.81 * * *$ & $0.87 * * *$ & $0.89 * * *$ & $0.86 * * *$ & $0.86 * * *$ & $0.63 * * *$ & $0.83 * * *$ & $0.93 * * *$ \\
\hline Model & GJR & TARCH & GARCH & $\begin{array}{c}\text { TS- } \\
\text { GARCH }\end{array}$ & GARCH & GARCH & GARCH & $\begin{array}{c}\text { TS- } \\
\text { GARCH }\end{array}$ & $\begin{array}{c}\text { TS- } \\
\text { GARCH }\end{array}$ & $\begin{array}{c}\text { TS- } \\
\text { GARCH }\end{array}$ & GARCH \\
\hline
\end{tabular}

High negative

Neutral

High positive

Significance levels: $* 10 \%, * * 5 \%, * * * 1 \%$

Notes: The model parameters in Panel A include asymmetry effects $(\gamma)$, GARCH effects $(\beta)$ and ARCH effects $(\alpha)$. See notes on Table 4. 
Table 6: Non-Founding members' market reaction to euro adoption announcement and the euro adoption event, conditional mean equation

\begin{tabular}{|c|c|c|c|c|c|c|c|}
\hline Country & GR & SI & $\mathbf{C Y}$ & MT & EE & $\mathbf{L V}$ & $\mathbf{L T}$ \\
\hline \multicolumn{8}{|c|}{ Panel A: euro announcement events } \\
\hline Dnews.gr & $-13.69 *$ & & & & & & \\
\hline Dnews.si & 1.01 & -3.80 & & & & & \\
\hline Dnews.mt.cy & 2.03 & $-8.18^{+}$ & 0.61 & -3.88 & & & \\
\hline Dnews.sk & -2.11 & 2.07 & $13.87^{+}$ & $-5.92^{+}$ & & & \\
\hline Dnews.ee & 6.28 & -3.93 & -3.76 & -3.01 & 3.90 & & \\
\hline Dnews.lv & 4.74 & -- & -7.99 & -2.08 & -6.38 & -4.22 & \\
\hline Dnews.lt & -1.10 & -- & 6.19 & 0.87 & -2.02 & -3.14 & -0.11 \\
\hline \multicolumn{8}{|c|}{ Panel B: euro introduction events } \\
\hline Deuro.gr & -3.83 & & & & & & \\
\hline Deuro.si & 6.42 & $14.11 * * *$ & & & & & \\
\hline Deuro.mt.cy & -2.67 & $-8.18^{+}$ & 1.04 & -1.20 & & & \\
\hline Deuro.sk & -2.11 & $8.92^{+}$ & 11.87 & -3.33 & & & \\
\hline Deuro.ee & 5.08 & -- & 10.08 & 0.63 & -0.06 & & \\
\hline Deuro.lv & 0.56 & -- & -0.20 & -2.58 & -2.29 & 4.86 & \\
\hline Deuro.lt & $-18.6 * * *$ & -- & $-16.40^{+}$ & -1.55 & 4.93 & 1.52 & -1.47 \\
\hline \multicolumn{8}{|c|}{ Panel C: control variables } \\
\hline Constant & 0.15 & 0.13 & -1.66 & 0.41 & 0.87 & 1.06 & 0.75 \\
\hline Market spillover & $0.97 * * *$ & 0.09 & $1.29 * * *$ & $0.18 * * *$ & $0.41 * * *$ & $0.22 * *$ & $0.27 * * *$ \\
\hline ESI, EA & $-1.61 *$ & -0.62 & $-2.22^{+}$ & -0.07 & -0.07 & 0.70 & 0.21 \\
\hline ESI, EU & $1.61 *$ & $1.33 *$ & $3.35 *$ & 0.39 & 0.72 & -0.15 & $0.93^{+}$ \\
\hline M1 & -0.51 & 0.06 & -0.38 & 0.48 & 0.37 & 0.11 & 0.32 \\
\hline \multicolumn{8}{|c|}{ Country-level controls } \\
\hline ESI & $0.51 * *$ & $0.25 *$ & 0.02 & 0.06 & $0.55 * *$ & $0.54 *$ & 0.17 \\
\hline $\begin{array}{l}\text { Industrial } \\
\text { production }\end{array}$ & $-0.32 *$ & $0.26^{+}$ & $0.88^{+}$ & -0.09 & $0.52 * * *$ & $0.24^{+}$ & $0.11^{+}$ \\
\hline Unemployment & $-0.04 * *$ & $-0.04^{+}$ & $-0.07^{+}$ & -0.00 & -0.00 & 0.00 & $-0.02^{+}$ \\
\hline Inflation & $-0.76^{*}$ & 0.77 & -0.54 & -0.28 & -1.04 & $-1.27^{+}$ & -0.48 \\
\hline \multicolumn{7}{|l|}{ High negative } & h positive \\
\hline
\end{tabular}

Significance levels: * $10 \%, * * 5 \%, * * * 1 \%$

Notes: see notes on Table 4. Slovakia is not presented in the rest of the analysis due to many missing observations in the data. 
Table 7: Non-Founding members' market reaction to euro adoption announcement and the euro adoption event, conditional variance equation

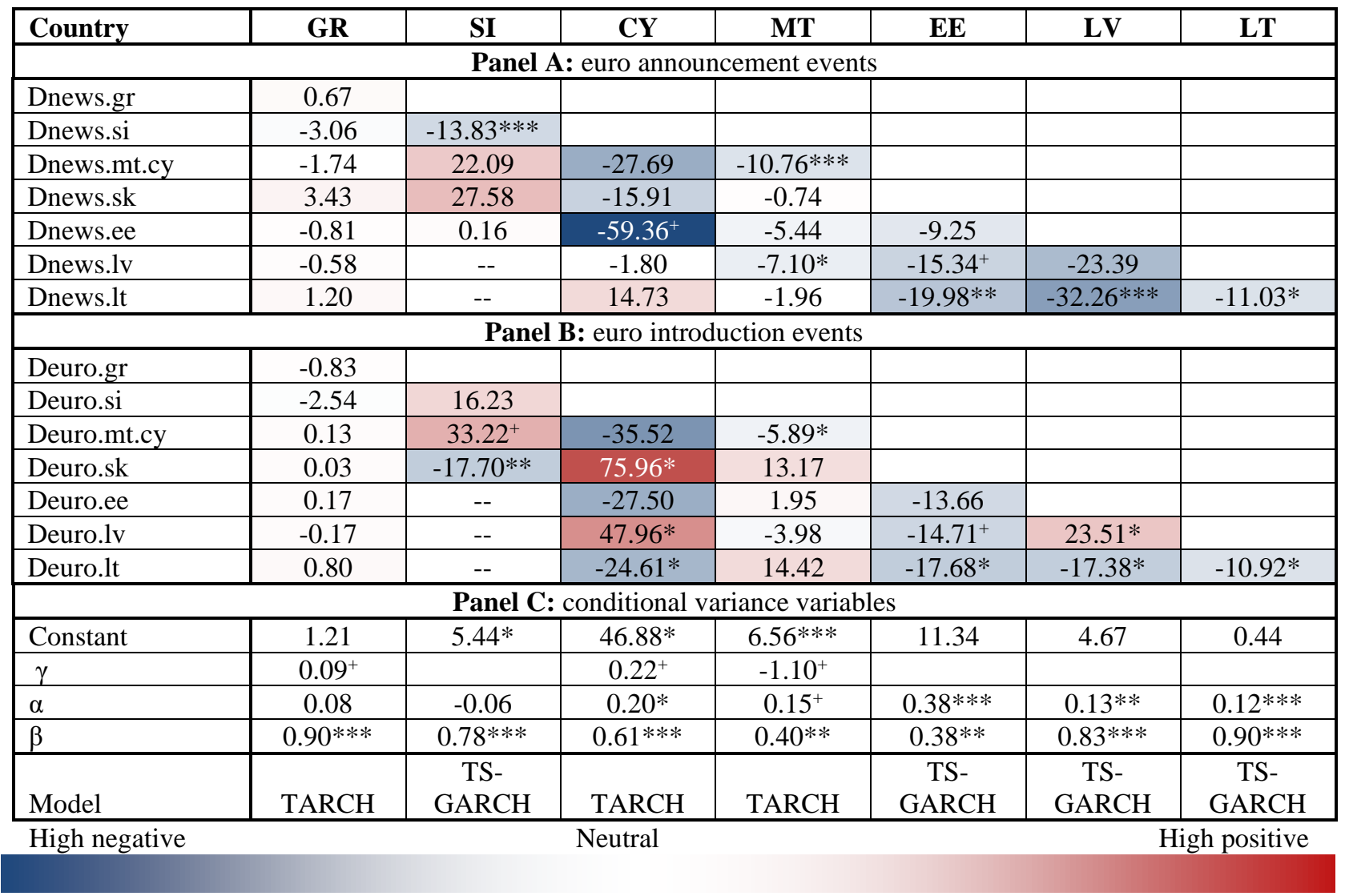

Significance levels: $* 10 \%, * * 5 \%, * * * 1 \%$

Notes: see notes on Table 5. 
Figure 1: Stock Market Volatility in Slovenia and the euro area, 2006-2007

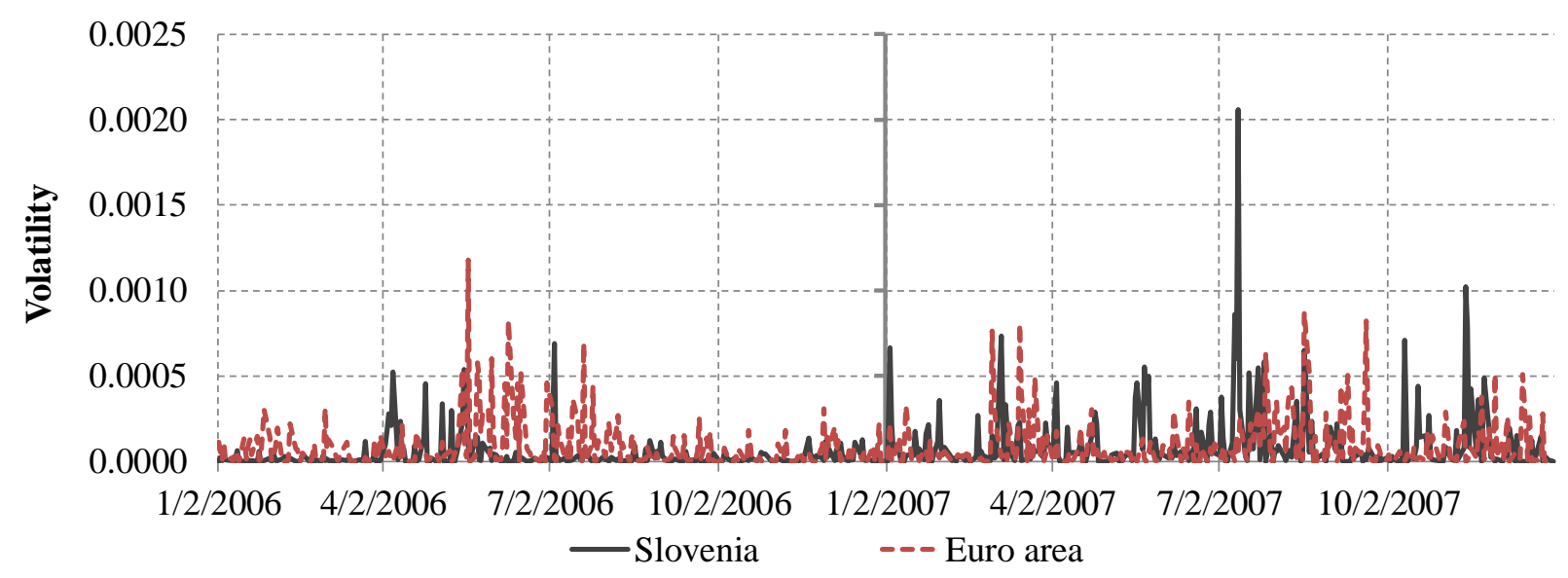

Note: volatility is calculated as squared log daily returns. Authors calculations based on Bloomberg data.

Figure 2: Stock Market Volatility in Lithuania and the euro area, 2014-2015

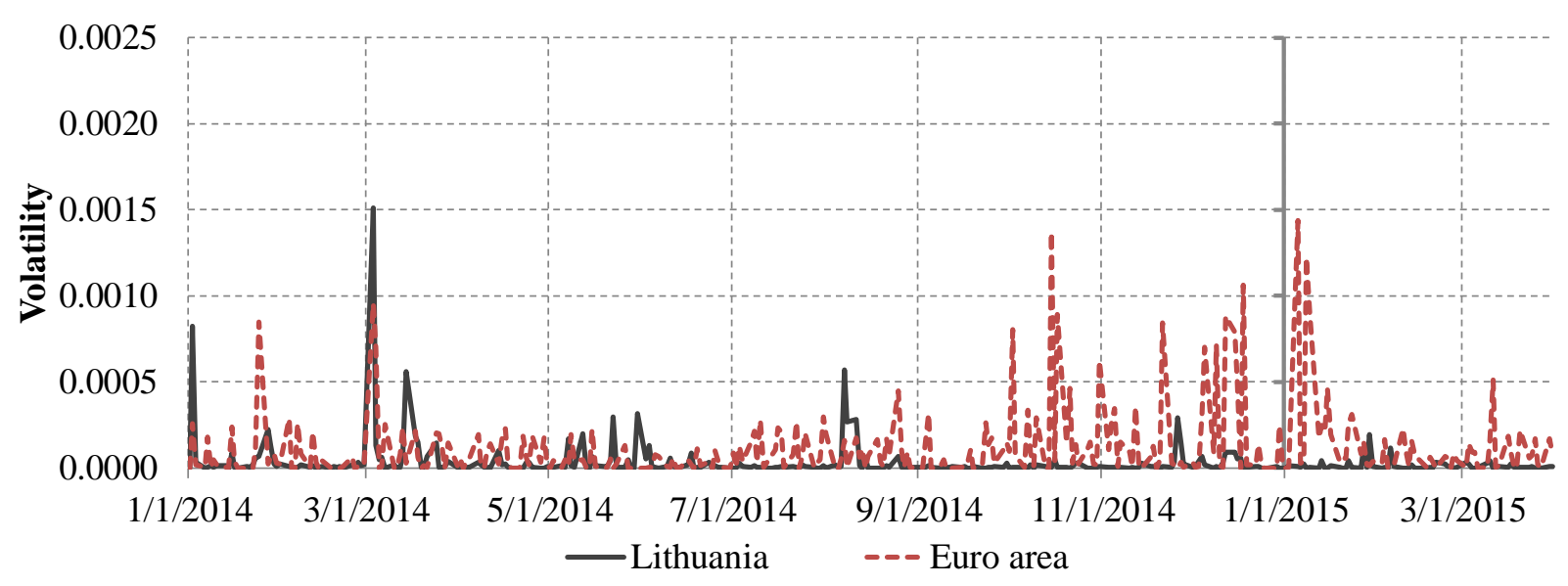

Note: volatility is calculated as squared log daily returns. Authors calculations based on Bloomberg data. 
Figure 3: Cumulative abnormal returns in founding euro members
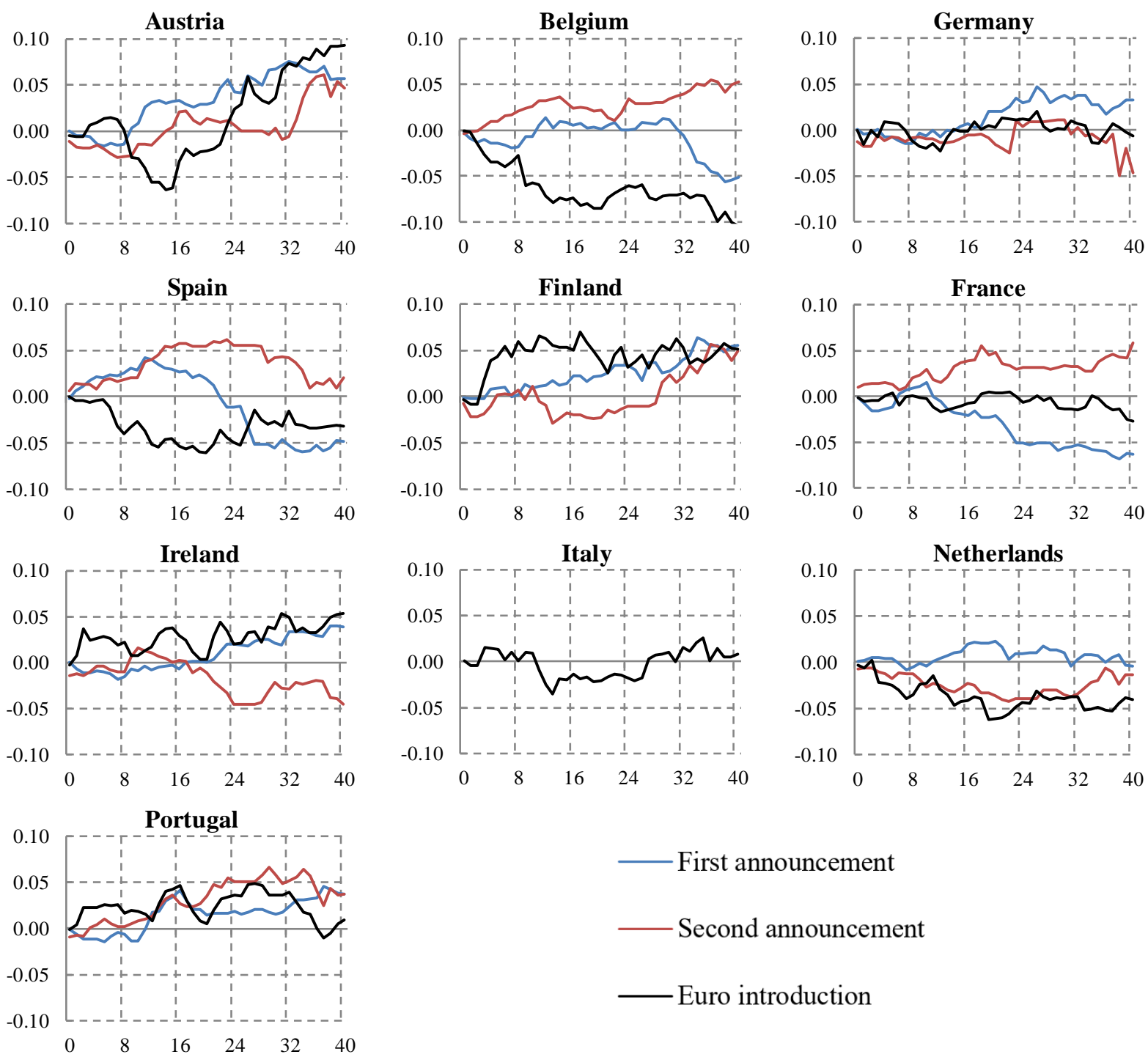

_ First announcement

- Second announcement

- Euro introduction 
Figure 4: Founding members' heat map of abnormal returns to the first, second announcements of the euro introduction and the euro introduction events.

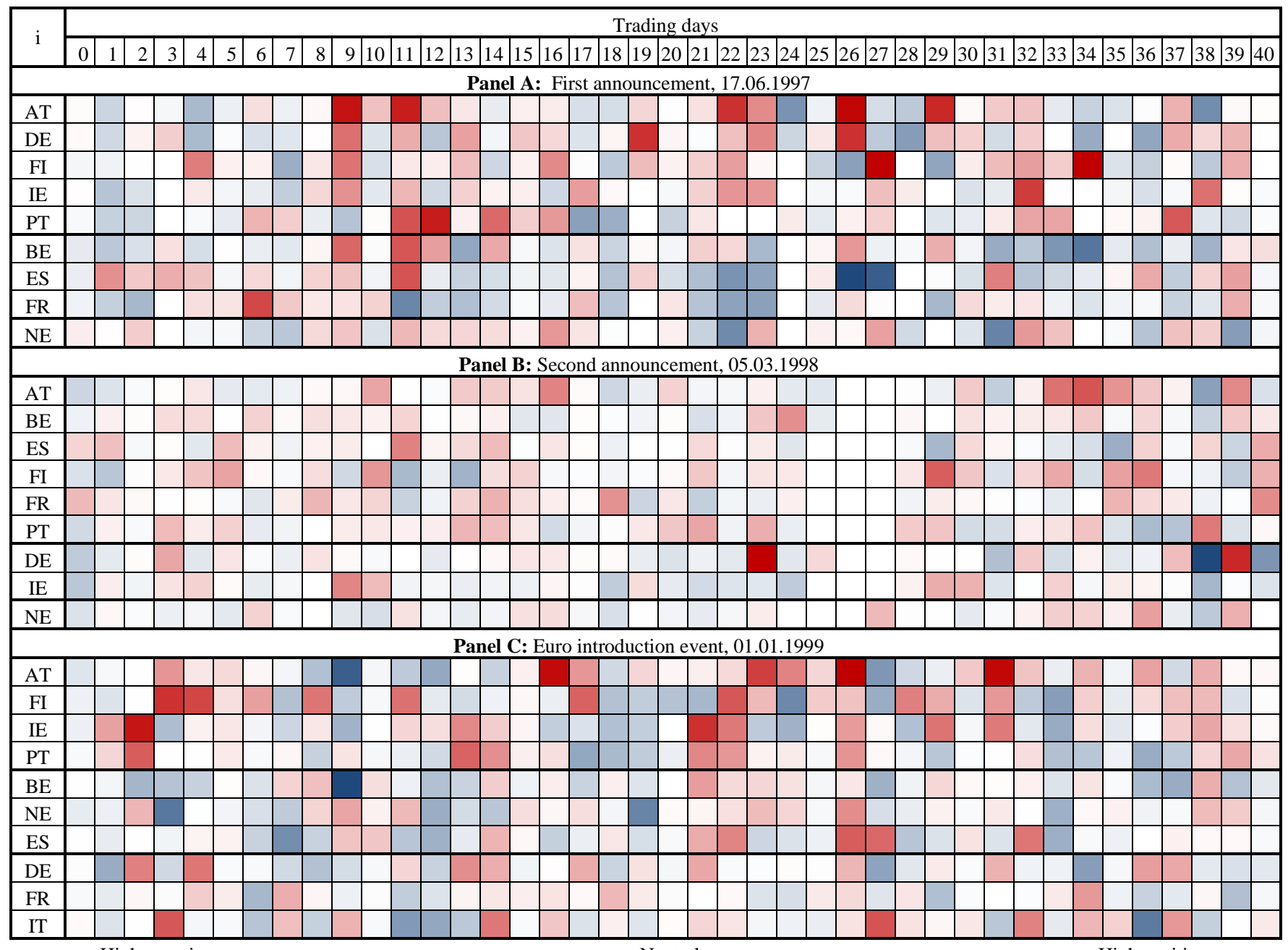

High negative

Neutral

High positive

Notes: The heat map depicts abnormal daily returns (ARs), where darkest blue color represents the largest negative values, while dark red color the largest positive values of ARs for each corresponding panel. Neutral values represent close to zero ARs. The magnitude of ARs does not imply the statistical significance of deviations. Significant values are marked in Table 1. 
Figure 5: Cumulative abnormal returns in non-founding euro members
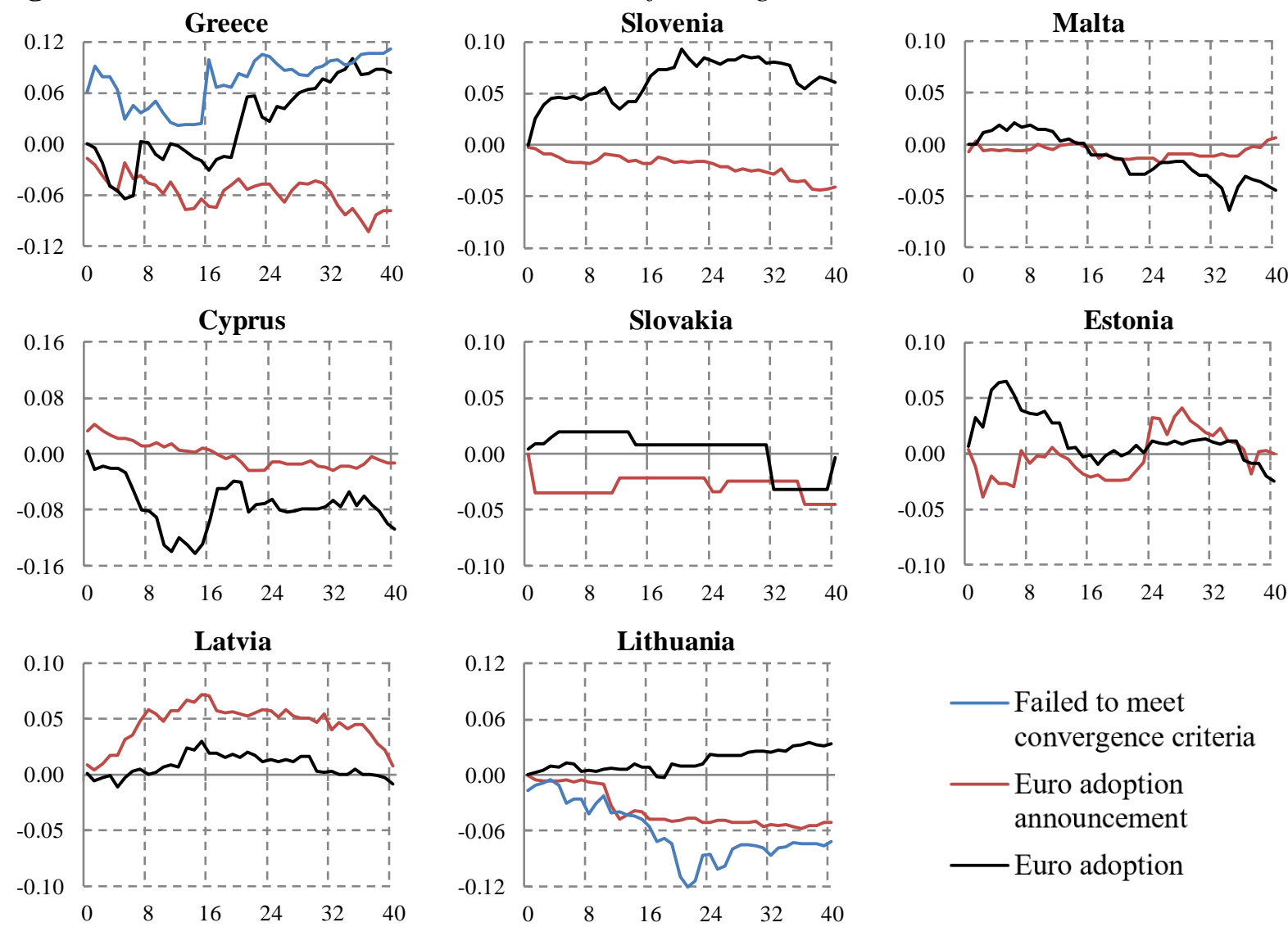

- Failed to meet convergence criteria

— Euro adoption announcement

— Euro adoption 
Figure 6: Non-Founding members' heat map of abnormal returns with the euro adoption announcement and the euro adoption events.

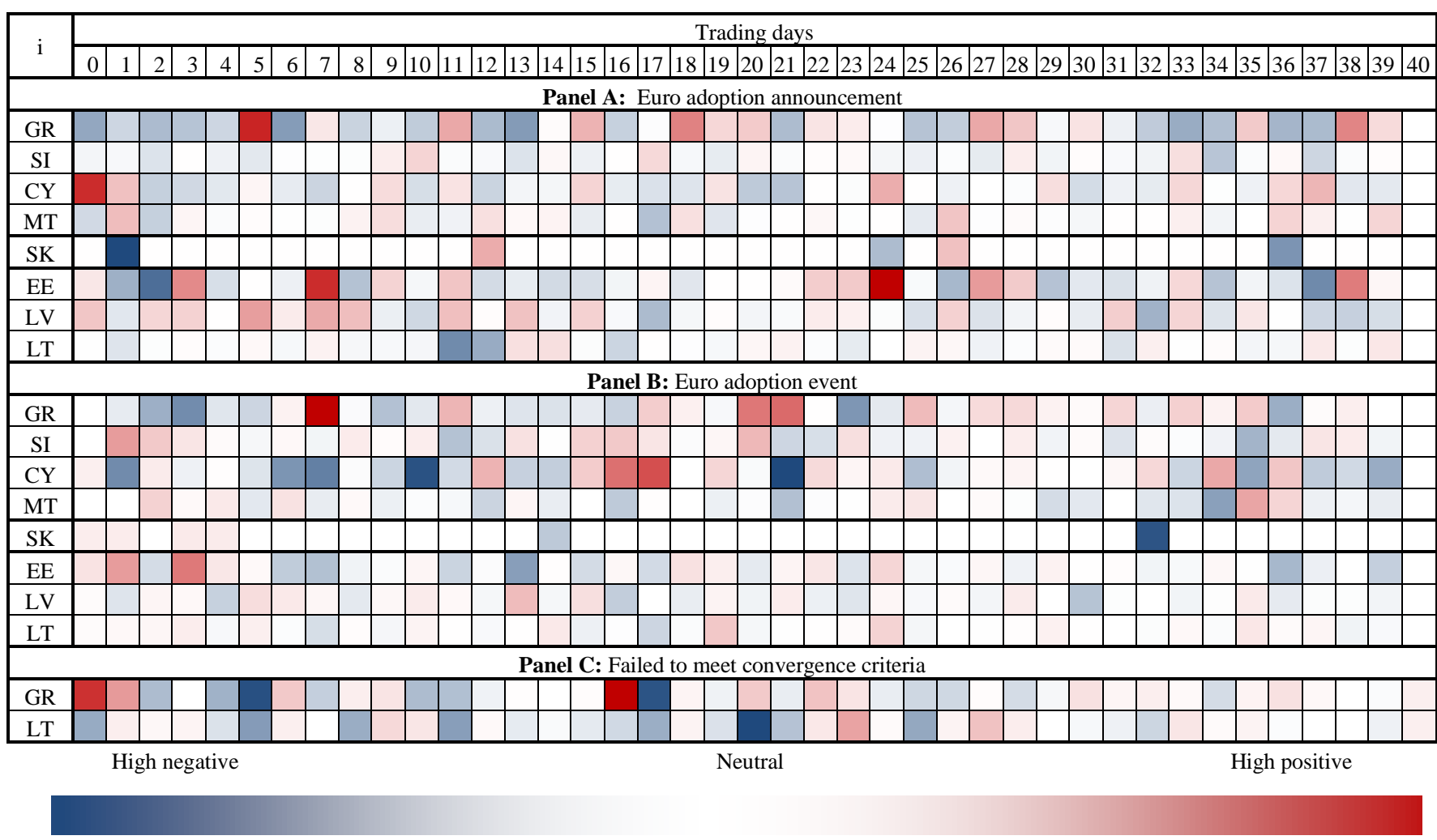

Notes: see notes on Figure 4. For corresponding dates of events see Appendix 1 and significant ARs in Table 2. 


\section{Appendix 1. Country notations and euro events dates.}

\begin{tabular}{|c|c|c|c|c|c|}
\hline $\begin{array}{c}\text { Country } \\
\text { code, } \\
\text { CC }\end{array}$ & Country & $\begin{array}{c}\text { Euro introduction } \\
\text { news } 1^{\text {st }} \text { stage for } \\
11 \text { founding } \\
\text { members, } \\
\text { D1news }\end{array}$ & $\begin{array}{c}\text { Euro introduction } \\
\text { news } 2^{\text {nd }} \text { stage for } \\
11 \text { founding } \\
\text { members. D2news }\end{array}$ & $\begin{array}{c}\text { Euro adoption } \\
\text { news, Dnews.CC }\end{array}$ & $\begin{array}{c}\text { Euro introduction } \\
\text { date, Deuro } \\
\text { Euro adoption date, } \\
\text { Deuro.CC }\end{array}$ \\
\hline AT & Austria & 17.06 .1997 & 05.03 .1998 & & 01.01 .1999 \\
\hline BE & Belgium & 17.06 .1997 & 05.03 .1998 & & 01.01 .1999 \\
\hline DE & Germany & 17.06 .1997 & 05.03 .1998 & & 01.01 .1999 \\
\hline ES & Spain & 17.06 .1997 & 05.03 .1998 & & 01.01 .1999 \\
\hline FI & Finland & 17.06 .1997 & 05.03 .1998 & & 01.01 .1999 \\
\hline FR & France & 17.06 .1997 & 05.03 .1998 & & 01.01 .1999 \\
\hline IE & Ireland & 17.06 .1997 & 05.03 .1998 & & 01.01 .1999 \\
\hline IT & Italy & 17.06 .1997 & 05.03 .1998 & & 01.01 .1999 \\
\hline LU & Luxemburg & 17.06 .1997 & 05.03 .1998 & & 01.01 .1999 \\
\hline NE & Netherlands & 17.06 .1997 & 05.03 .1998 & & 01.01 .1999 \\
\hline PT & Portugal & 17.06 .1997 & 05.03 .1998 & & 01.01 .2001 \\
\hline GR & Greece & & $05.03 .1998 *$ & 20.06 .2000 & 01.01 .2007 \\
\hline SI & Slovenia & & & 03.02 .2006 & 01.01 .2008 \\
\hline MT & Malta & & & 16.05 .2007 & 01.01 .2008 \\
\hline CY & Cyprus & & & 05.07 .2007 & 01.01 .2009 \\
\hline SK & Slovakia & & & 07.03 .2010 & 01.01 .2011 \\
\hline EE & Estonia & & & 23.07 .2014 & 01.01 .2015 \\
\hline LV & Latvia & & & & 01.2014 \\
\hline LT & Lithuania & & & & \\
\hline
\end{tabular}

Notes: * denotes the natural experiment events when Greece and Lithuania failed to meet the convergence criteria and enter the euro area in early years with founding members and Slovenia correspondingly.

Appendix 2. Descriptive statistics, daily stock market returns.

\begin{tabular}{|c|r|r|r|r|r|r|r|}
\hline $\mathrm{i}$ & \multicolumn{1}{|c|}{ Mean } & \multicolumn{1}{c|}{ Median } & Minimum & Maximum & Std. Dev. & Skewness & Ex. kurtosis \\
\hline AT & -0.0001 & 0.0010 & -0.0870 & 0.0526 & 0.0131 & -1.0055 & 5.2157 \\
\hline BE & 0.0010 & 0.0014 & -0.0448 & 0.0445 & 0.0108 & -0.1380 & 1.6869 \\
\hline DE & 0.0011 & 0.0024 & -0.0838 & 0.0611 & 0.0157 & -0.7546 & 3.0796 \\
\hline ES & 0.0013 & 0.0017 & -0.0672 & 0.0573 & 0.0145 & -0.5375 & 3.4616 \\
\hline FI & 0.0016 & 0.0030 & -0.0859 & 0.0970 & 0.0168 & -0.4523 & 4.5643 \\
\hline FR & 0.0011 & 0.0012 & -0.0563 & 0.0610 & 0.0143 & -0.2103 & 1.9921 \\
\hline IE & 0.0011 & 0.0015 & -0.0757 & 0.0583 & 0.0111 & -0.6399 & 7.0860 \\
\hline IT & 0.0014 & 0.0030 & -0.0636 & 0.0699 & 0.0211 & -0.1876 & 0.6666 \\
\hline LU & -0.0010 & -0.0015 & -0.0179 & 0.0120 & 0.0075 & -0.1225 & -0.3366 \\
\hline NE & 0.0011 & 0.0022 & -0.0612 & 0.0573 & 0.0155 & -0.3819 & 1.8605 \\
\hline PT & 0.0015 & 0.0016 & -0.0959 & 0.0694 & 0.0138 & -0.8879 & 7.9272 \\
\hline GR & -0.0005 & -0.0014 & -0.0962 & 0.0762 & 0.0211 & 0.1359 & 2.0605 \\
\hline SI & 0.0009 & 0.0004 & -0.0635 & 0.0556 & 0.0090 & -0.3267 & 7.8483 \\
\hline MT & -0.0004 & -0.0003 & -0.0297 & 0.0345 & 0.0067 & 0.0508 & 4.6162 \\
\hline CY & 0.0007 & 0.0006 & -0.0885 & 0.0836 & 0.0171 & -0.3182 & 3.8057 \\
\hline SK & -0.0032 & 0.0003 & -0.3298 & 0.2843 & 0.0554 & -0.7587 & 17.4090 \\
\hline EE & 0.0023 & 0.0014 & -0.0575 & 0.1209 & 0.0154 & 1.3192 & 8.1301 \\
\hline LV & 0.0007 & 0.0005 & -0.0358 & 0.0329 & 0.0079 & -0.1724 & 1.4701 \\
\hline LT & 0.0003 & 0.0002 & -0.0384 & 0.0291 & 0.0055 & -0.6139 & 10.1050 \\
\hline
\end{tabular}

Notes: summary statistics are provided for samples, where event studies models were estimated, and vary from 1.5 to 2.5 years depending on the country case. Negative values for skewness show that market returns below the median are typically larger in magnitude than above median. High values for excess kurtosis mean that outliers are more likely than for normal distribution. 
Appendix 3. Descriptive statistics, monthly stock market returns.

\begin{tabular}{|c|c|c|c|c|c|c|c|}
\hline $\mathrm{i}$ & Mean & Median & Minimum & Maximum & Std. Dev. & Skewness & Ex. kurtosis \\
\hline AT & 0.3640 & 1.0430 & -32.5940 & 13.5470 & 6.2709 & -1.3110 & 4.2949 \\
\hline BE & 0.3437 & 1.0735 & -24.0880 & 13.5140 & 5.0667 & -1.3646 & 3.6102 \\
\hline DE & 0.6860 & 1.4967 & -29.3330 & 19.3740 & 6.4787 & -0.9347 & 2.7507 \\
\hline ES & 0.5494 & 0.9654 & -21.5140 & 15.1910 & 5.9657 & -0.5364 & 1.0458 \\
\hline FI & 0.7121 & 1.2344 & -31.3220 & 25.7510 & 7.7692 & -0.3363 & 2.0468 \\
\hline FR & 0.3968 & 1.2334 & -19.2250 & 12.5880 & 5.5443 & -0.6019 & 0.5755 \\
\hline IE & 0.4119 & 1.2670 & -23.5820 & 17.8250 & 5.8565 & -0.9685 & 2.0317 \\
\hline IT & -0.0253 & 0.4565 & -18.3080 & 19.0890 & 6.4861 & -0.2349 & 0.6804 \\
\hline LU & 0.2866 & 1.0579 & -31.2050 & 16.6460 & 6.7946 & -1.3198 & 4.4766 \\
\hline NE & 0.3313 & 1.2182 & -22.6220 & 14.5690 & 5.9745 & -1.0148 & 2.2119 \\
\hline PT & 0.1450 & 0.5363 & -23.3480 & 17.1920 & 6.0838 & -0.4948 & 1.3605 \\
\hline GR & -0.1060 & 0.2222 & -32.6730 & 34.5950 & 9.5172 & -0.1528 & 1.2152 \\
\hline SI & 0.4759 & 0.4487 & -20.6910 & 28.4990 & 6.6009 & 0.0366 & 2.5628 \\
\hline MT & 0.5790 & -0.0778 & -10.8300 & 22.6780 & 4.9457 & 1.1539 & 3.1253 \\
\hline CY & -2.2187 & -1.0982 & -53.4420 & 38.0550 & 14.7600 & -0.3360 & 1.0556 \\
\hline SK & -0.3921 & -0.0557 & -36.1010 & 22.6770 & 7.6009 & -1.2778 & 7.2628 \\
\hline EE & 0.9862 & 1.1147 & -44.9770 & 37.0330 & 9.8791 & -0.6968 & 4.7779 \\
\hline LV & 0.7323 & 0.6294 & -27.0750 & 29.2340 & 6.7212 & -0.3394 & 4.3035 \\
\hline LT & 0.8654 & 0.9356 & -35.0910 & 36.0760 & 7.2522 & -0.4754 & 6.5816 \\
\hline
\end{tabular}

Notes: summary statistics are provided for the whole available data samples. Values for logarithmic returns are multiplied by factor 100, hence it could be interpreted as percentage changes. Negative values for skewness show that market returns below the median are typically larger in magnitude than above the median. High values for excess kurtosis mean that outliers are more likely than for normal distribution.

Appendix 4. Descriptive statistics, monthly stock market volatility.

\begin{tabular}{|c|c|c|c|c|c|c|c|}
\hline $\mathrm{i}$ & Mean & \multicolumn{1}{c|}{ Median } & Minimum & Maximum & Std. Dev. & Skewness & Ex. kurtosis \\
\hline AT & 41.7910 & 12.8710 & 0.0000 & 901.1200 & 91.2860 & 5.2483 & 37.4290 \\
\hline BE & 39.1540 & 10.1950 & 0.0003 & 1086.2000 & 98.4490 & 7.1986 & 64.9380 \\
\hline DE & 25.5600 & 7.9046 & 0.0001 & 596.9000 & 60.6720 & 5.6954 & 40.7510 \\
\hline ES & 35.4350 & 9.6524 & 0.0002 & 486.8000 & 61.9760 & 3.4145 & 15.8810 \\
\hline FI & 60.0970 & 17.3860 & 0.0000 & 1026.2000 & 121.1600 & 4.0984 & 21.7180 \\
\hline FR & 30.6060 & 11.6380 & 0.0013 & 385.0300 & 49.2250 & 3.1924 & 13.8880 \\
\hline IE & 34.1500 & 11.0850 & 0.0041 & 575.7200 & 68.7200 & 4.1738 & 21.6700 \\
\hline IT & 41.8670 & 14.7650 & 0.0000 & 365.3400 & 68.7100 & 2.8116 & 8.2497 \\
\hline LU & 45.9280 & 11.7390 & 0.0001 & 991.6900 & 117.1900 & 5.8398 & 38.7060 \\
\hline NE & 35.5390 & 9.9070 & 0.0017 & 526.8400 & 73.0970 & 4.2732 & 21.6610 \\
\hline PT & 36.8510 & 12.7150 & 0.0007 & 551.9100 & 67.7020 & 3.9073 & 19.3220 \\
\hline GR & 90.1840 & 27.0310 & 0.0000 & 1204.1000 & 162.0600 & 3.7301 & 17.5370 \\
\hline SI & 43.3260 & 10.3770 & 0.0007 & 785.3000 & 92.8100 & 4.4919 & 26.0970 \\
\hline MT & 24.3540 & 6.3467 & 0.0000 & 488.3800 & 55.2560 & 5.5906 & 39.6710 \\
\hline CY & 216.1400 & 55.7580 & 0.0076 & 2623.8000 & 379.3200 & 3.3106 & 14.1600 \\
\hline SK & 57.1600 & 2.6180 & 0.0023 & 1275.1000 & 174.9000 & 4.8602 & 27.0510 \\
\hline EE & 97.1630 & 19.3900 & 0.0005 & 2112.6000 & 253.5200 & 4.9254 & 27.6710 \\
\hline LV & 44.9270 & 9.5811 & 0.0010 & 812.3400 & 113.1100 & 4.9381 & 27.4810 \\
\hline LT & 52.3050 & 10.7550 & 0.0000 & 1292.9000 & 153.6500 & 6.3459 & 44.4130 \\
\hline
\end{tabular}

Notes: see appendix 3. Volatility is defined as zero-mean squares of monthly logarithmic returns. 


\section{Appendix 5. Financial openness in the euro area}

Existing studies of financial integration have largely focused on general measures of financial openness (Bekaert G. , et al., 2007); mostly due to the limited availability of the balance of payments data on the bilateral foreign direct investments. In order to ascertain if financial integration was a factor in the responses to euro introduction, we have fashioned a financial openness indicator, by taking the sum of absolute values of inward and outward financial flows and dividing it over the sum of partner GDPs (Herrero \& Ruiz, 2008):

$$
F O Y_{i j}=\frac{100}{T} \sum_{t=1}^{T} \frac{a_{i t}+l_{i t}+a_{j t}+l_{j t}}{y_{i t}+y_{j t}}
$$

where $a_{i t}$ denotes the assets of country $i$ at year $t$ (outward FDI flow), $l_{i t}$ are stands for corresponding liabilities (inward FDI flow) and $y_{i t}$ is the nominal GDP. The time average taken over 1999-2017 allows us to smooth the impacts of both business and financial cycles and also accounts for the usage of financial flows instead of investment positions.

The results of this exercise are shown in Figure A1, which clusters the countries of the euro area into three groups applying Ward's hierarchical agglomerative clustering method (Murtagh \& Legendre, 2014). The small and open economies in the upper left and middle clusters are also likely to have high levels of financial openness; this could be positive, in that these countries will reap the benefits of cross-border investment, portfolio diversification, and foreign bank involvement, but it may also have negative consequences in terms of exposure to international conditions. By contrast, the medium and largest euro area economies in the lower right cluster appear capable of financing their economic activities utilizing domestic financial resources, being relatively more insulated. Most importantly, in line with the results presented in the main text, it appears that the most financially open countries were also those which welcomed the euro's expansion the most. 
Figure A1: Financial openness in the euro area, 1999-2017.

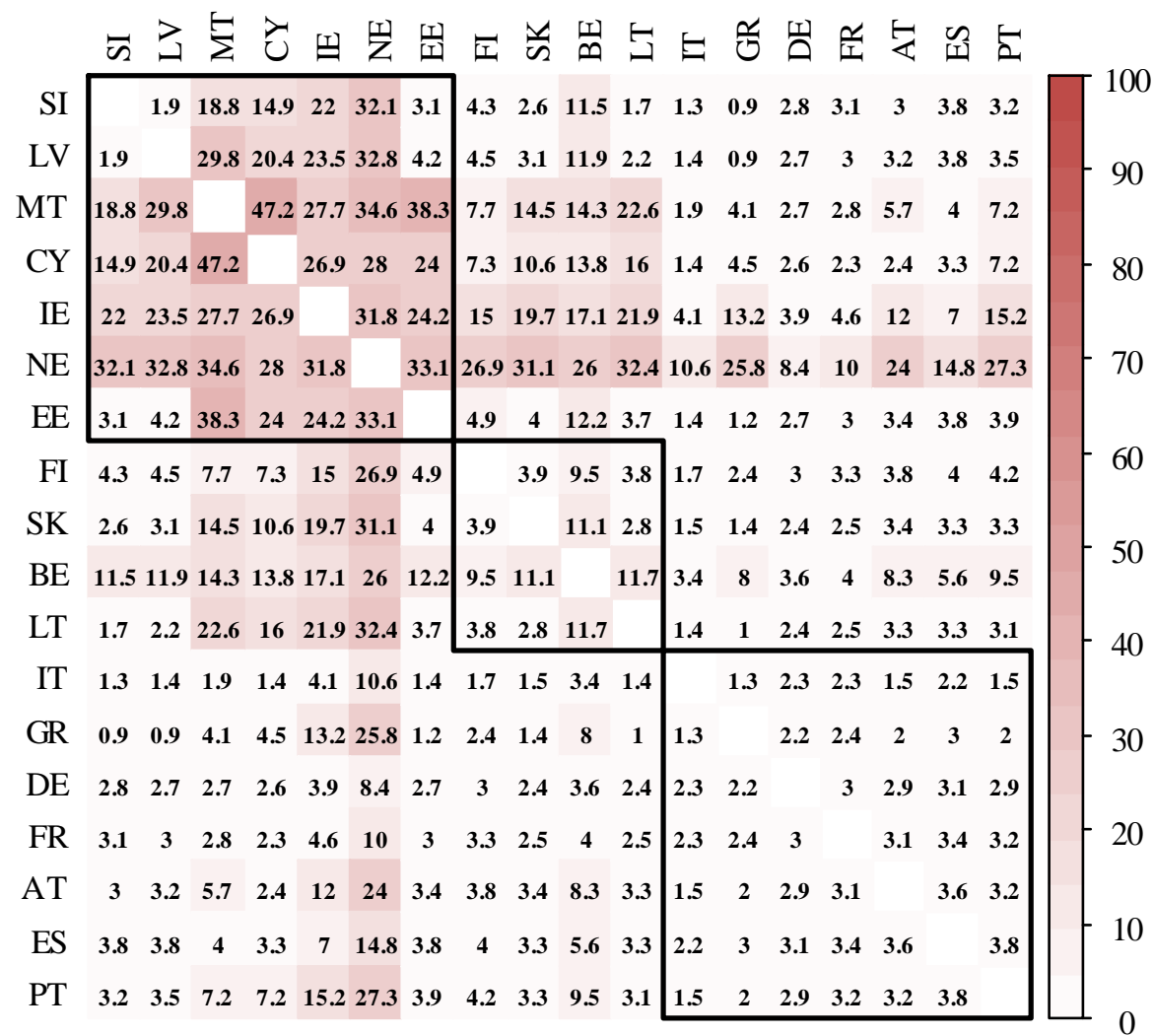

Source: Eurostat, authors' calculations.

Notes: Luxembourg was excluded from the estimation as an outlier. 


\section{Appendix 6. Trade integration in the euro area}

It can be plausibly argued that real trade linkages, rather than financial channels, may condition a country's response to the expansion of the euro. Measures of trade linkages differ across studies (Böwer \& Guillemineau, 2006; Herrero \& Ruiz, 2008), with early studies widely using trade openness, defined as the sum of total exports and imports of both countries, divided by the sum of national GDPs. In our paper, following Böwer and Guillemineau (2006) we instead fashion a tradenormalized bilateral trade measure:

$$
B T T_{i j}=\frac{100}{T} \sum_{t=1}^{T} \frac{x_{i j t}+m_{i j t}+x_{j i t}+m_{j i t}}{x_{i t}+m_{i t}+x_{j t}+m_{j t}},
$$

where $x_{i j t}$ denotes the exports of country $i$ to country $j$ at year $t, m_{i j t}$ are stands for corresponding imports, $x_{i t}$ and $m_{i t}$ represent total exports and imports of country $i$. The time average taken over 2000-2017 allows us to smooth the impacts of both business and financial cycles. Alternatively, similar to the financial openness indicator shown in the previous section, the scaling variable could be the sum of national GDPs, although we eschew this approach here.

As with the financial openness indicator, the countries were clustered into three groups applying Ward's hierarchical agglomerative clustering method (Murtagh \& Legendre, 2014). Figure A2 reveals that intra-trade integration also shows three distinct clusters within the euro area: the most integrated countries, perhaps not surprisingly the original members of the EU, with smaller countries incredibly integrated; the Baltic countries, forming their own cluster and highly integrated with each other but not very integrated with the rest of the EA; and the rest of euro area members with no particular intra-trade concentration with other members. This third group is comprised generally of new members who have not had the same opportunities within the EU (i.e. due to a shorter lifespan) to forge trade linkages. 
Figure A2: Trade integration in the euro area, 2000-2017.

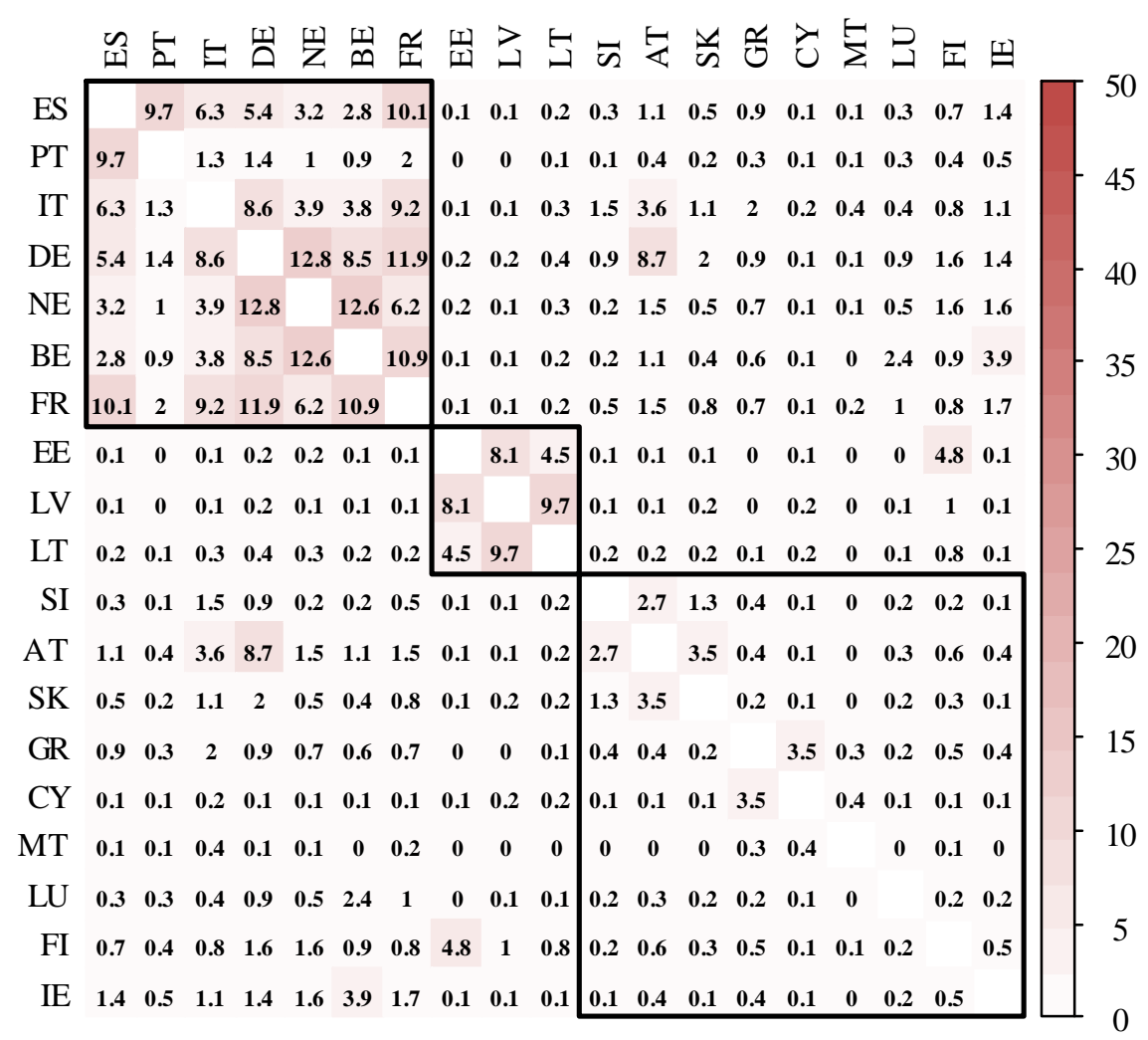

Source: Eurostat, authors' calculations.

Notes: The sample starts in 2000 due to the lack of intra EU and extra EU trade data in 1999. 